EXTENDED REPORT

\title{
The achiasmia spectrum: congenitally reduced chiasmal decussation
}

\author{
D A Sami, D Saunders, D A Thompson, I M Russell-Eggitt, K K Nischal, G Jeffery, M Dattani, \\ R A Clement, A Liassis, D S Taylor
}

Br J Ophthalmol 2005;89:1311-1317. doi: 10.1136/bjo.2005.068171

See end of article for authors' affiliations

.......................

Correspondence to: Dr D S Taylor, Visual Sciences Unit, Institute of Child Health, 30 Guilford Street, London WCIN 1EH, UK; d.taylor@ich.udl. ac.uk

Accepted for publication 23 March 2005
Aim: To describe the clinical spectrum of achiasmia, a congenital disorder of reduced relative decussation at the optic chiasm.

Methods: A retrospective case note and patient review of nine children (four boys). Achiasmia was defined by the combination of a characteristic asymmetry of the monocular visual evoked potential (VEP) response to flash and neuroimaging showing reduced chiasmal size.

Results: Three of the children had an associated skull base encephalocele with agenesis of the corpus callosum. In two patients achiasmia was associated with septo-optic dysplasia. Three patients had no neuroimaging abnormalities other than reduced chiasmal size and have no known pituitary dysfunction. One child had multiple physical deformities but the only brain imaging abnormality was reduced chiasmal size.

Conclusions: Some children with disorders of midline central nervous system development, including septo-optic dysplasia and skull base encephaloceles, have congenitally reduced chiasmal decussation. Reduced relative decussation may co-exist with overall chiasmal hypoplasia. Children with an apparently isolated chiasmal decussation deficit may have other subtle neurological findings, but our clinical impression is that most of these children function well.
$\mathrm{T}$ he optic chiasm, shaped liked the letter $X$, is named after the Greek letter chi $(\chi)$. Decussation of retinal fibres at the chiasm appears to be the evolutionary "default pathway" and the amount of ipsilateral projection correlates with binocular specialisation. ${ }^{1}{ }^{2}$ Clinically, most cases are due to acquired abnormalities caused by compression, trauma, or inflammation. In some individuals, decussation of retinal ganglion cell axons at the chiasm is selectively reduced during development. ${ }^{3}{ }^{4}$ Abnormal decussation could be the result of disruption in molecular mechanisms that guide midline axonal crossing. This is an area of active molecular genetic research. Signalling pathways have been identified that produce an achiasmic phenotype-for instance, retinal axons do not decussate in Pax-2 deficient mice, entering the ipsilateral optic tract instead. ${ }^{5}$ When Pax-2 is blocked, Sonic hedgehog expression at the ventral midline is prolonged. ${ }^{7}$ Other molecular pathways implicated in midline attraction or avoidance of retinal ganglion cell axons include CD44 (a surface bound adhesion molecule), ${ }^{8}$ Zic2 (a zinc finger transcription factor), ${ }^{2}$ and the Ephrins. ${ }^{9-11}$ An alternative to the molecular genetic paradigm is a vascular disruption sequence; during embryogenesis branches of the anterior cerebral artery supply the chiasm, anterior hypothalamus, and septum pellucidum. ${ }^{12}$ In humans, chiasmal decussation of nerve fibres and development of the contralateral optic radiation has been reported despite unilateral optic nerve aplasia. ${ }^{13}$

Abnormalities of decussation can be revealed by hemispheric asymmetry of monocular visual evoked potentials (VEP). ${ }^{414}$ In humans, both reduced (in achiasmia) ${ }^{15} 16$ and excess (in albinism) ${ }^{17}$ decussation correlate with nystagmus. However, a VEP asymmetry does not necessarily predict readily visible nystagmus-as shown in albinism. ${ }^{14}{ }^{18}$ Significant asymmetry of the monocular VEP response is not always found in albinism with nystagmus. ${ }^{19} 20$

Complete absence of the chiasm (chiasmal aplasia) may not be associated with other significant CNS abnormalities: a girl with bilateral microphthalmos, bilateral aplasia of the optic nerves, chiasm and tracts had no other apparent abnormalities and was developing normally up to the age of 3.5 years. ${ }^{21}$ Also, aplasia of the chiasm was associated only with optic nerve hypoplasia and polymicrogyria. ${ }^{22}$

The term "non-decussating retinal fugal fibre syndrome" (NDRFFS) has been used to describe isolated absence of chiasmal crossing. ${ }^{23}$ There is an animal model-a strain of Belgian sheep dogs with absent chiasmal decussation and the combination of horizontal and seesaw nystagmus. ${ }^{24}$ The clinical features of NDRFFS are combined horizontal and seesaw nystagmus, an achiasmic VEP pattern, absence of endocrine abnormalities, normal visual fields, and normal foveal reflexes. ${ }^{15}{ }^{23}$ To our knowledge, the state of their optic discs on ophthalmoscopy has not been photographically detailed in the literature ${ }^{3152325-27}$ but is described as normal. ${ }^{25-27}$ Head "shudder" or "tremor", torticollis, and alternating esotropia have been reported in at least three of four reported patients with the combined horizontal and seesaw nystagmus of NDRFFS. ${ }^{15} 26$ Nystagmus in patients with a range of chiasmal disorders may be classically "seesaw", but nystagmus is not necessarily present and may be of many less specific types.

There are other cases in which reduced chiasmal decussation does not fall within the strict criteria of NDRFFS. A retrospective case note and patient review was undertaken to define better the clinical spectrum of achiasmia.

\section{METHODS}

\section{Patient selection}

From the records of the Great Ormond Street Hospital (GOSH) Ophthalmology Department, nine children (four boys) aged 4-14 years were identified with a diagnosis of

Abbreviations: NDRFFS, non-decussating retinal fugal fibre syndrome; VEP, visual evoked potential 
achiasmia. All of these children had previously been clinically examined and had undergone clinically appropriate neuroimaging and VEP studies. One patient had died before the start of this study, three were re-examined at routine follow up visits to GOSH, one (who had been previously evaluated at GOSH) was reviewed locally by a paediatric ophthalmologist, and four were reviewed specially at GOSH. Inclusion criteria were presence of nystagmus, VEP documentation of consistent positive contralateral crossed asymmetry to flash, ${ }^{16}$ and reduced chiasmal size on neuroimaging. Where appropriate, VEPs and eye movement studies were repeated.

Data on ocular motility, strabismus, refraction, and visual acuity were recorded and the anterior segment and fundi were examined in all cases. Whenever possible, eye movements, fundus photographs, and formal visual fields were recorded. All previous hospital notes were reviewed.

The study was approved by the Great Ormond Street Hospital and the Institute of Child Health (University College London) research ethics committee

\section{Electrophysiology}

VEPs to flash ${ }^{16}$ were recorded from three occipital electrodes-one placed $2-3 \mathrm{~cm}$ above the inion and two placed midway between the inion and mastoid process. Simultaneously, flash electroretinograms were recorded from skin electrodes placed along the inferior eyelid margin.

\section{Eye movement recording}

Quantitative measurements of eye movements were made with an infrared limbus tracking system (Skalar Medical, Delft, The Netherlands). Horizontal movements were recorded from the right eye and vertical movements were recorded from the left eye. A chin rest was used to stabilise the head and the subject was asked to fixate on a red LED light subtending a quarter of a degree of visual angle. The eye movement recordings were calibrated by asking the subjects to fixate additional positions spaced \pm 15 degrees apart horizontally and \pm 5 degrees apart vertically. Video recordings of eye movements were also made to facilitate interpretation of the quantitative eye movement recordings.

\section{Neuroimaging}

All previous brain neuroimaging results were reviewed to confirm reduced chiasmal size and to review other associated brain deformities.

\section{RESULTS}

The case records and clinical examination results of the nine children are shown in table 1 . The appearance of the optic nerves and relevant neuroimaging is shown in figs l-9: fundus photographs were not available for cases 2 and 4 and only one fundus was available for case 9. All patients had a characteristic pattern of monocular VEP asymmetry to a flash of light (the VEPs for case 1 are shown in fig II and for case 6 in fig 6G). ${ }^{16}$ Three of the children had a skull base encepahalocele and agenesis of the corpus callosum (cases 6, 7 and 8). In two patients achiasmia was associated with septo-optic dysplasia, a combination of absent septum pellucidum, optic nerve hypoplasia, and hypopituitarism ${ }^{12}$ (cases 4 and 5). Three children had no neuroimaging abnormalities other than reduced chiasmal size and have no known pituitary dysfunction (cases 1, 2 and 3); however, one had mild Asperger syndrome and one had subclinical epileptiform seizure activity. One child had multiple deformities including microtia, hemifacial microsomia, oesophageal atresia, and hydronephrosis; the only brain imaging abnormality was reduced chiasmal size (case 9).

Corrected acuities varied widely: one eye had 0.1 LogMAR, the others between perception of light and 0.5, 10 eyes had between 0.5 and 0.6. Eight patients had a best corrected binocular acuity of at least 0.6 LogMAR (table 1). All children had normal colour vision as tested with Ishihara colour plates. Stereo acuity as tested with Titmus fly and/or TNO stereo acuity tests was recorded as absent in all patients. No specific pattern of nystagmus was common to the study patients. The sample includes pure horizontal, rotary, and compound rotary or circumrotary and horizontal nystagmus (table 1). Further details can be seen on the video available on the journal website (http://bjo.bmjjournals.com/supplemental)

Our patients seem mostly to fall into three subtypes: type A (three patients) with isolated achiasmia on neuroimaging,

\begin{tabular}{|c|c|c|c|c|c|c|c|}
\hline $\begin{array}{l}\text { Case } \\
\text { no }\end{array}$ & Sex & Type* $^{*}$ & Age (years) & Refraction & $\begin{array}{l}\text { Visual acuity } \\
\text { (logMAR) }\end{array}$ & Nystagmus & Strabismus \\
\hline 1 & M & A & 9 & $\begin{array}{l}\mathrm{RE}-1.50+0.50 \times 90 \\
\mathrm{LE} 0.00+1.00 \times 90\end{array}$ & $\begin{array}{l}1.0 \\
0.6\end{array}$ & $\begin{array}{l}\text { Horizontal } \\
\mathrm{R} \text { head turn }\end{array}$ & $\begin{array}{l}\text { XT small angle } \dagger \\
V \text { pattern }\end{array}$ \\
\hline 2 & $\mathrm{~F}$ & A & 4 & $\begin{array}{l}\text { RE } 0.00+0.50 \times 90 \\
\operatorname{LE} 0.00+1.50 \times 90\end{array}$ & $\begin{array}{l}0.6 \\
0.5\end{array}$ & $\begin{array}{l}\text { Horizontal } \\
\text { Horizontal }\end{array}$ & $\begin{array}{l}X T \text { small angle } \\
\mathrm{V} \text { pattern }\end{array}$ \\
\hline 3 & $\mathrm{~F}$ & A & 12 & $\begin{array}{l}\mathrm{RE}+1.50 \mathrm{sph} \\
\mathrm{LE}+1.50 \mathrm{sph}\end{array}$ & $\begin{array}{l}0.1 \\
0.6\end{array}$ & $\begin{array}{l}\text { Minimal rotary nystagmus } \\
\text { Amplitude } L>>R\end{array}$ & ET small angle \\
\hline 4 & $\mathrm{~F}$ & B & 4 & $\begin{array}{l}\mathrm{RE}+1.00 \mathrm{sph} \\
\mathrm{LE}+2.00 \mathrm{sph}\end{array}$ & $\begin{array}{l}\text { Very poor } \\
0.6\end{array}$ & Rotary + horizontal & Right XT angle 30 \\
\hline 5 & $\mathrm{~F}$ & B & 12 & $\begin{array}{l}\mathrm{RE}+3.0 \mathrm{sph} \\
\mathrm{LE}+1.0+4.0 \times 90\end{array}$ & $\begin{array}{l}\text { Greater than } 1.0 \\
0.6\end{array}$ & $\begin{array}{l}\text { Highly variable } \\
\text { Horizontal and vertical } \\
\text { (not seesaw) }\end{array}$ & Right ET angle 45 \\
\hline 6 & $\mathrm{~F}$ & C & 10 & $\mathrm{RE}-5.00-1.00 \times 80$ & 0.7 & $\begin{array}{l}\text { Seesaw variant: circumrotary } \\
\text { + dysconjugate vertical }\end{array}$ & No detectable strabismus \\
\hline 7 & M & C & 14 & $\begin{array}{l}\mathrm{LE}-3.50-2.50 \times 120 \\
\mathrm{RE}-0.50+1.00 \times 90 \\
\mathrm{LE}+1.00+1.00 \times 90\end{array}$ & $\begin{array}{l}0.5 \\
0.8 \\
0.5\end{array}$ & $\begin{array}{l}\text { Horizontal } \\
\text { Left beating, rotary } \\
\text { component in } 1^{\circ}\end{array}$ & No detectable strabismus \\
\hline 8 & M & C & Deceased & $\begin{array}{l}\mathrm{RE}-4.50+2.00 \times 120 \\
\mathrm{LE}-1.50+1.00 \times 180\end{array}$ & $\begin{array}{l}\text { Greater than } 1.0 \\
1.0\end{array}$ & Type unclear & Vertical gaze palsy \\
\hline 9 & M & Other & 6 & $\begin{array}{l}\mathrm{RE}+0.50+1.00 \times 120 \\
\mathrm{LE}+0.50+0.50 \times 90\end{array}$ & $\begin{array}{l}0.6 \\
0.6\end{array}$ & $\begin{array}{l}\text { Horizontal } \\
\text { Head shake }\end{array}$ & No detectable strabismus \\
\hline
\end{tabular}

$\mathrm{XT}$ = exotropia; $\mathrm{ET}$ = esotropia

*Type: $A=$ no other midline abnormality on imaging except small chiasm; B = septo-optic dysplasia (optic nerve hypoplasia, hypopituitarism, deficient septum pellucidum); $C$ = skull base encephalocele + agenesis of the corpus callosum + hypopituitarism.

†Angle of strabismus in prism dioptres. 

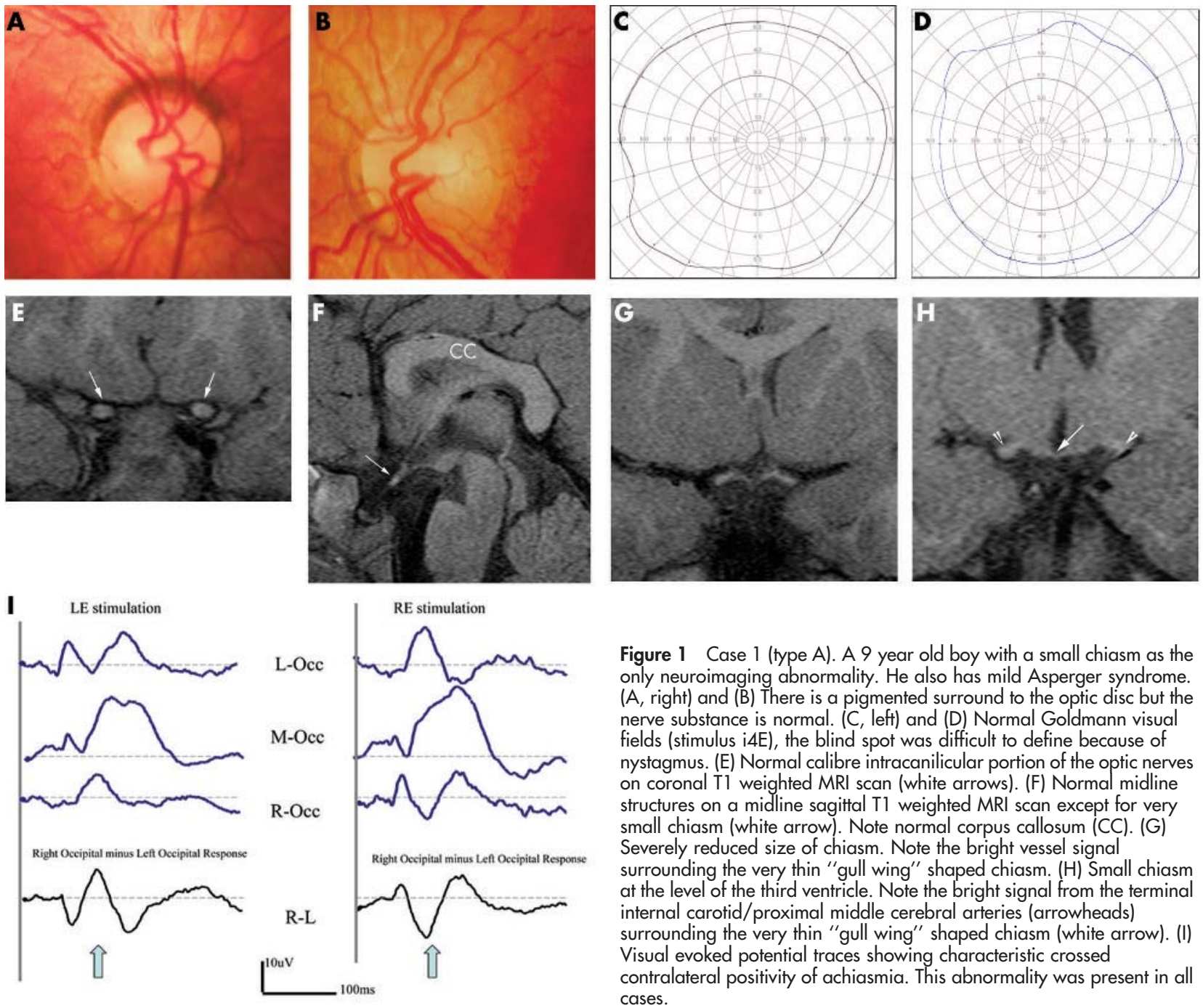

Figure 1 Case 1 (type A). A 9 year old boy with a small chiasm as the only neuroimaging abnormality. He also has mild Asperger syndrome. ( $A$, right) and (B) There is a pigmented surround to the optic disc but the nerve substance is normal. (C, left) and (D) Normal Goldmann visual fields (stimulus i4E), the blind spot was difficult to define because of nystagmus. (E) Normal calibre intracanilicular portion of the optic nerves on coronal T1 weighted MRI scan (white arrows). (F) Normal midline structures on a midline sagittal TI weighted MRI scan except for very small chiasm (white arrow). Note normal corpus callosum (CC). (G) Severely reduced size of chiasm. Note the bright vessel signal surrounding the very thin "gull wing" shaped chiasm. (H) Small chiasm at the level of the third ventricle. Note the bright signal from the terminal internal carotid/proximal middle cerebral arteries (arrowheads) surrounding the very thin "gull wing" shaped chiasm (white arrow). (I) Visual evoked potential traces showing characteristic crossed contralateral positivity of achiasmia. This abnormality was present in all cases.

type B (two patients) with septo-optic dysplasia, and type C (three patients) with skull base encephalocele and agenesis of the corpus callosum (table 1). One patient (case 9) did not fit into any of these groups.

\section{DISCUSSION}

\section{Definition and classification of achiasmia}

There is probably some chiasmal hypoplasia whenever there is optic nerve hypoplasia. In most of these cases, normal proportions of retinal ganglion cell axons have been directed ipsilaterally and contralaterally but, overall, are fewer in number. The optic chiasm in achiasmia is not just hypoplastic but it has the essential absence or relative lack of crossing fibres; thus, optic nerve hypoplasia and achiasmia may coexist (figs 5A and B, 6A and B, 7B). The term "achiasmia" may strictly suggest an absence of the chiasm but, for clarity, it is used here to identify the essential abnormality of crossing fibres. Complete absence of the chiasmal structure, often associated with optic nerve aplasia, is thus not achiasmia; the term "chiasmal aplasia" is more appropriate. $^{21} 22$

The definition of achiasmia is therefore not as strict as NDRFFS (defined above). The criteria for diagnosis are positive contralateral asymmetry of the monocular VEP response to flash (figs $\mathrm{II}$ and $6 \mathrm{G}$ ) and neuroimaging showing reduced chiasmal size (figs $1 \mathrm{G}, 2,3 \mathrm{~A}$ and $\mathrm{B}, 4,5 \mathrm{C}, 6 \mathrm{E}, 8 \mathrm{D}$,

and 9B). Although nystagmus was part of the inclusion criteria for this study, it may not be a constant feature of achiasmia-just as the excess decussation in albinism is not inevitably associated with clinical nystagmus. ${ }^{18}$

To our knowledge, four patients (all female) have been reported with NDRFFS. ${ }^{15} 2326$ A fifth female has been described with isolated achiasmia but she only has horizontal nystagmus. ${ }^{25}$ The male:female ratio in our mixed group of patients with achiasmia is 4:5. One of three patients with isolated chiasmal deficit (our type A) is male (case 1). Another (case 9) who had an isolated small chiasm on neuroimaging but other associated facial and visceral problems is also male.

From our small sample and those in the literature, some general patterns appear to emerge. While the numbers of patients with this rare finding are small, we feel that there may be three main groups of patients with achiasmia:

- Type A: reduced decussation with optic nerves of normal appearance on clinical examination. ${ }^{25}{ }^{26}$ A small chiasm may be the only abnormality on the brain MRI scan. This group appears to overlap with NDRFFS. There may be seesaw $^{23}$ or purely horizontal ${ }^{25}$ nystagmus, and the visual fields appear to be normal. ${ }^{23}$ In our patients, cases 1 and 3 had normal formal visual fields, case 2 (who was 4 years old) had behaviourally normal fields. Abnormal head 


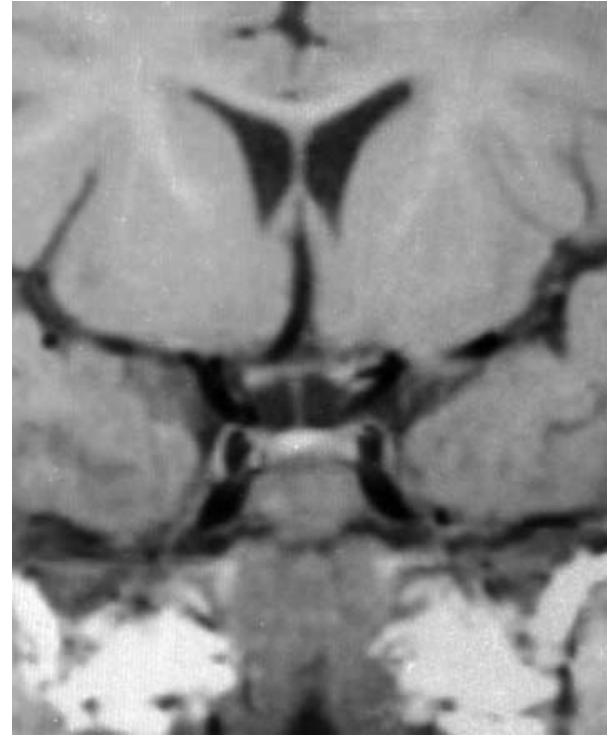

Figure 2 Case 2 (type A). A 4 year old girl with an isolated chiasmal deficit as the only neuroimaging abnormality. She was noted to have subclinical epileptiform activity. Optic nerve ophthalmoscopy was normal but photography was not possible. Behaviourally, the visual fields were normal and she has achieved all of her developmental milestones.

posture, strabismus, ${ }^{26}$ and other subtle neurological abnormalities (mild autism in case $\mathrm{l}$ and subclinical epileptiform temporal lobe activity in case 2) may be present.

- Type B: reduced decussation in combination with chiasmal hypoplasia and the midline defects of septo-optic dysplasia, ${ }^{16}{ }^{28}$ a combination of absent septum pellucidum, optic nerve hypoplasia, and hypopituitarism (cases 4 and 5). ${ }^{12}$

- Type C: reduced decussation and chiasmal hypoplasia in association with clefting disorders and encephaloceles of the skull base (cases 6, 7, and 8). Agenesis of the corpus callosum was present in all three of our patients with basal

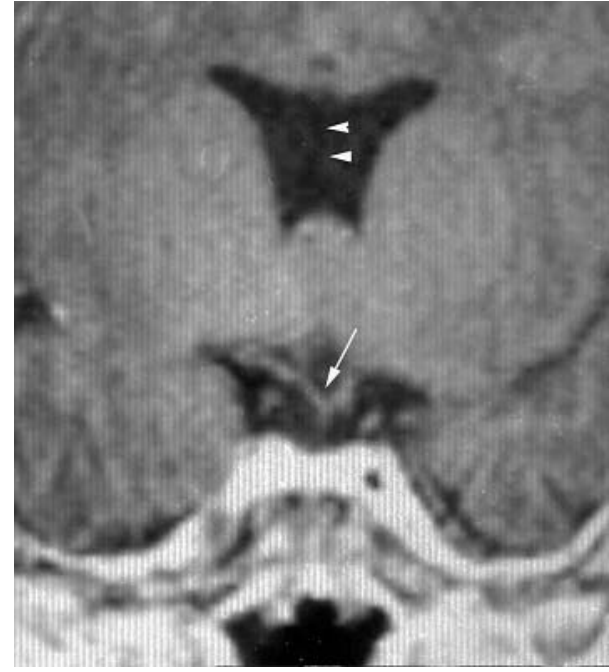

Figure 4 Case 4 (type B). A 4 year old girl with septo-optic dysplasia. On examination the left optic nerve was smaller than the right. Coronal Tl weighted images through the chiasmatic recess reveal the chiasm to be small and pulled down (arrow). The septum pellucidum is absent (arrowheads). Fundus photography was impossible due to lack of patient cooperation and nystagmus.

encephaloceles. The association of corpus callosum agenesis, morning glory disc, and optic nerve staphylomas with skull base encephaloceles has been previously reviewed. ${ }^{29}$

One patient in our series (case 9) did not fit into any of the above categories. This child suffered from multiple facial (microtia, hemifacial microsomia), visceral (oesophageal atresia, hydronephrosis), and developmental problems in addition to an isolated small chiasm; the MRI scan was otherwise normal.

\section{Visual fields in achiasmia}

Congenitally reduced chiasmal decussation need not be associated with visual field defects. The visual field may be
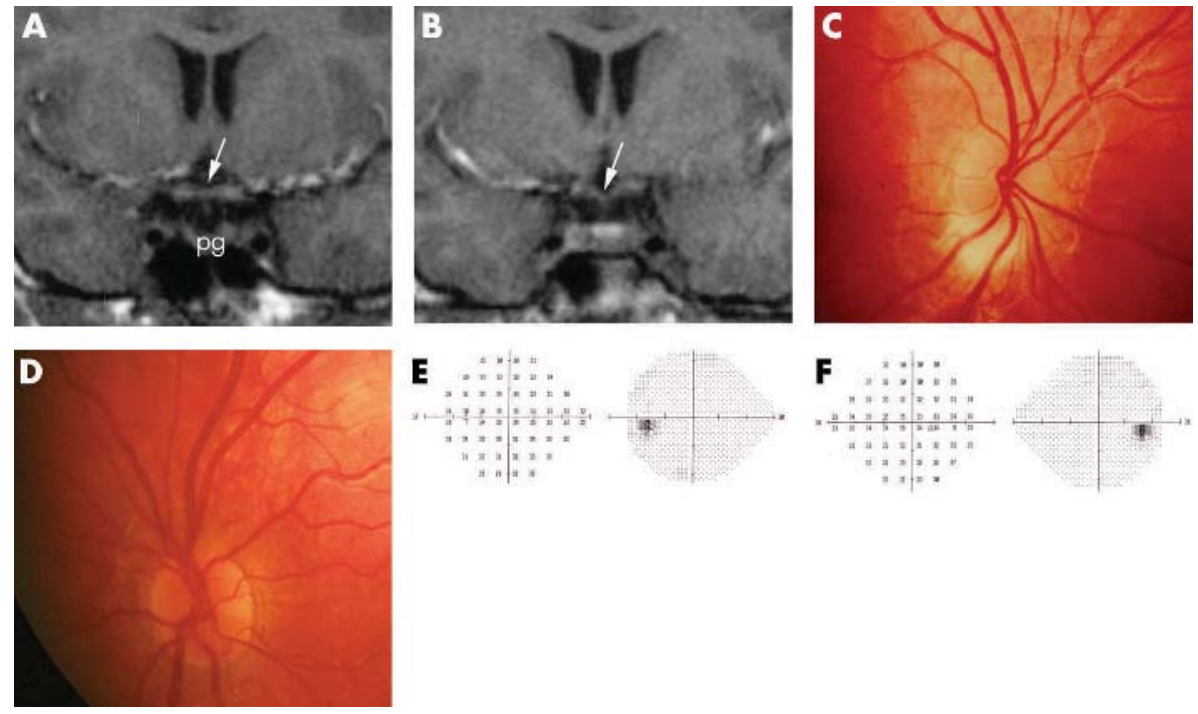

Figure 3 Case 3 (type A). A 12 year old girl with normal development and intelligence. (A) Serial coronal T1 weighted MRI scans showing an isolated small chiasm (arrows) through the level of the pituitary gland (pg). (B) More posterior section through the anterior third ventricle. Note the subtle bright vessel signal surrounding the very thin "gull wing" shaped chiasm similar to case 1. (C, right) and (D) The optic discs were normal; there was a small area of myelination inferior on the disc in the right eye. (E) and (F) Automated perimetry (30-2) was normal. 

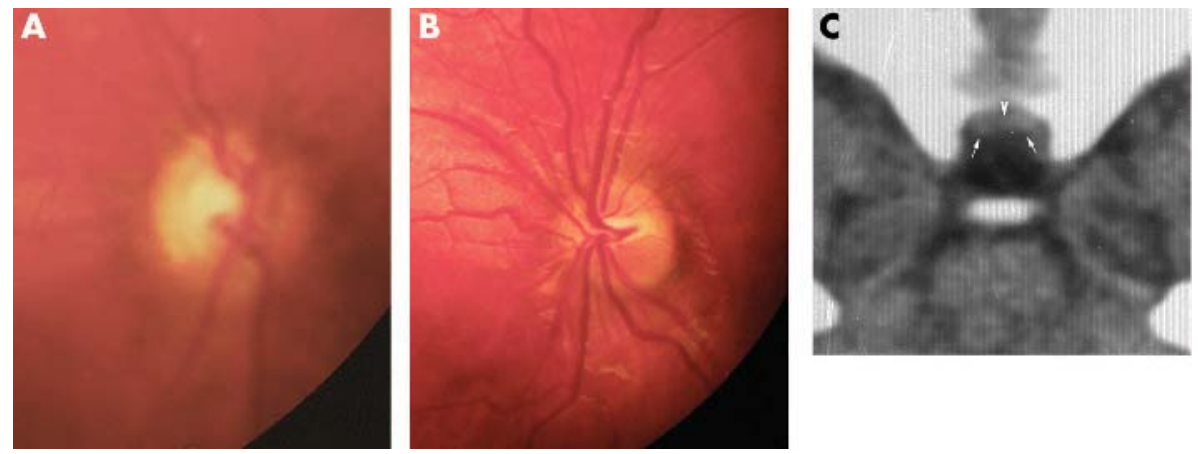

Figure 5 Case 5 (type B). A 12 year old girl with septo-optic dysplasia. (A) Optic nerve hypoplasia, right eye. (B) Band hypoplasia, left eye. Formal visual fields were not available but the appearances of the left optic disc suggest the likelihood of a left temporal hemianopia. (C) A coronal reformatted CT scan shows the optic nerves (arrows) but fails to reveal a chiasm suggesting that it is small (arrowhead).

abnormal due to optic nerve hypoplasia (case 6, fig 2) but does not necessarily have a bitemporal hemianopia pattern such as that seen with traumatic shearing of the chiasm. ${ }^{30-32}$

In cases 1 and 3 the appearance of the optic nerves and formal visual field testing were normal (figs $\mathrm{IC}$ and D, 3E and F) The finding of normal visual fields in association with an isolated small chiasm on neuroimaging has been reported previously. ${ }^{1523} 27$ A full visual field is consistent with studies of the lateral geniculate body (LGN) in the canine model of isolated achiasmia: misdirected nasal fibres form ipsilateral mirror image maps in those LGN layers that normally would have received nasal fibres from the contralateral eye. ${ }^{33}$ The optic discs may appear normal in achiasmia. ${ }^{25-27}$ The size of the optic nerves, density of axons, and total number of axons do not differ between achiasmic mutant and normal dogs, but the area centralis of the achiasmic dogs is smaller and has a lower peak ganglion cell density than that of normal dogs. ${ }^{34}$

\section{Seesaw nystagmus and achiasmia}

Seesaw nystagmus was described by Maddox in 1914. ${ }^{35}$ There is a conjugate torsional component and a dysconjugate vertical component. Both eyes rotate clockwise and then counterclockwise. The intorting eye rises while the extorting eye falls. However, the definition of seesaw nystagmus has
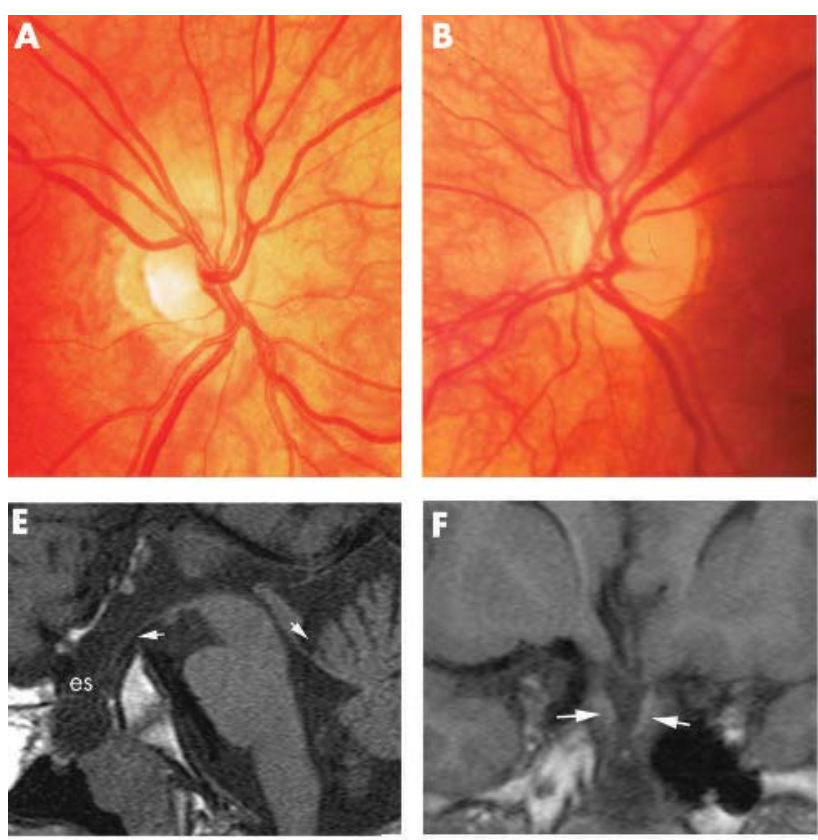

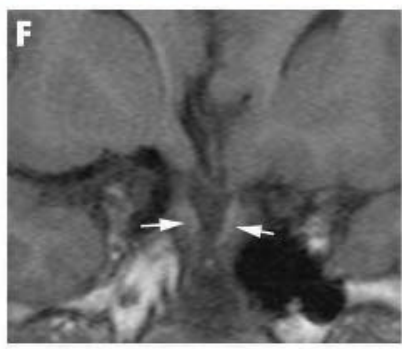

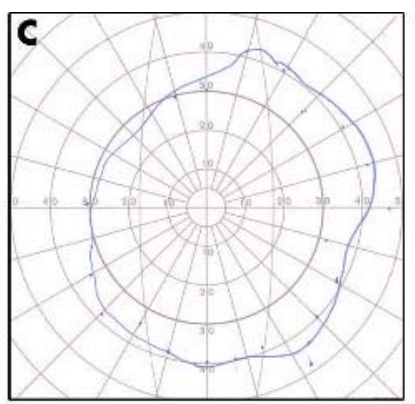

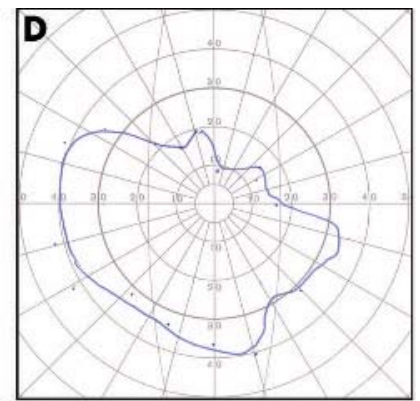

\section{G}

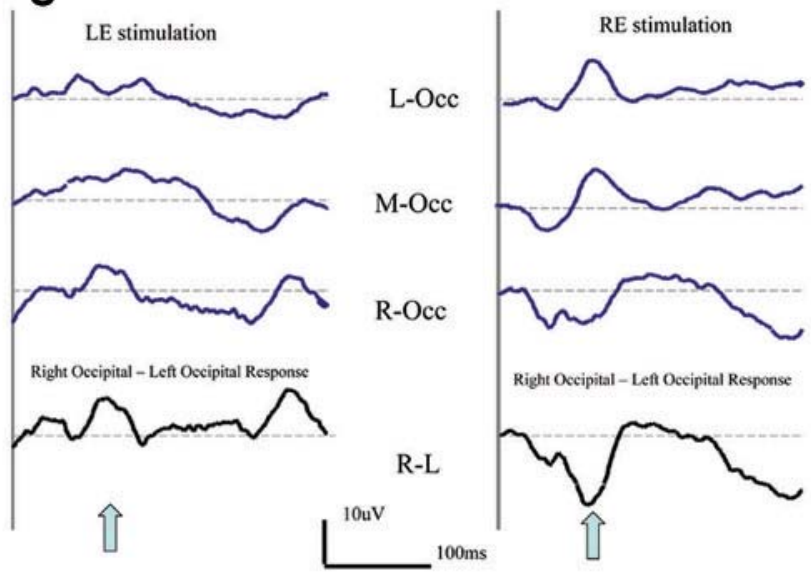

Figure 6 Case 6 (type C). Optic nerve hypoplasia in a 10 year old girl. (A) Right optic disc showing mild hypoplasia and inferotemporal pallor. (B) Leff optic disc showing possible mild hypoplasia and the suggestion of nasal pallor. (C) Left eye Goldmann visual field (stimulus IIVE) showing constriction, especially superotemporally. (D) Right visual field showing superior constriction consistent with the optic disc findings of inferior pallor. (E) Midline T1 weighted sagittal MRI scan showing absence of the corpus callosum, a large empty sella (es), and a very thin chiasm (arrow) (see fig $1 \mathrm{~F}$ for a normal corpus callosum). (F) Revised coronal Tl weighted MRI scan showing dragging of optic nerves (arrows) and chiasm into the repaired encephalocele. (G) VEP showing contralateral crossed asymmetry which, in combination with optic disc, visual fields, and MRI findings, demonstrates the co-existence of overall chiasmal hypoplasia and relative decussation deficit. Although not shown for every case, this finding was present in all. 

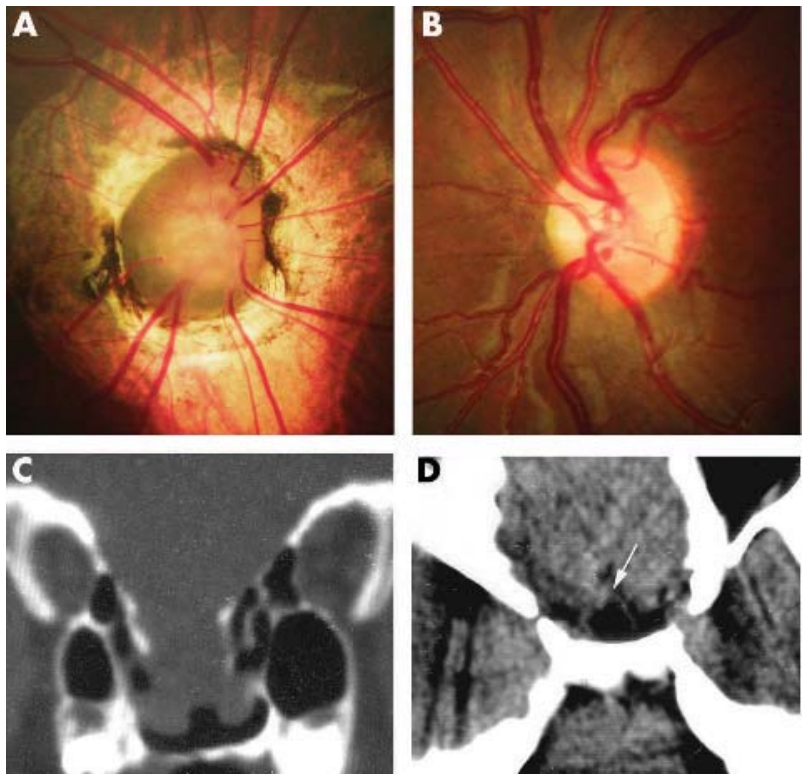

Figure 7 Case 7 (type C). A 14 year old boy with a cleff lip and palate, an ethmoidal encephalocele, and agenesis of the corpus callosum. (A) Morning glory disc, right eye. (B) Band optic atrophy, left eye. The presence of band atrophy in one eye and an abnormal disc of developmental origin in the other suggest that the cause of the band atrophy was most likely an early event, but it is possible that the band atrophy may have been caused by a postnatal event. (C) Coronal reformatted CT scan on bone windows showing a nasal encephalocele. (D) Soft tissue windows reveal an attenuated optic chiasm (arrow).

not remained strict over time. In 1946 Rucker $^{36}$ described seesaw nystagmus in a patient with vertical and torsional movements in the left eye (as described by Maddox), but only vertical movement in the right eye. Jensen described seesaw nystagmus as a "rare disjunctive form of vertical nystagmus in which the eyes perform opposed vertical movements", but did not specify a necessary torsional component. ${ }^{37}$

Disorders of the mesencephalon, ${ }^{38-40}$ chiasmal trauma, ${ }^{3031}$ and chiasmal compressive lesions ${ }^{41}{ }^{42}$ are associated with seesaw nystagmus. Achiasmia is a recent addition to the differential diagnosis of seesaw nystagmus. ${ }^{43}$

In initial reports the pattern of nystagmus in achiasmia was limited to the combination of congenital horizontal and seesaw nystagmus. ${ }^{43} 44$ However, purely horizontal nystagmus may be present in achiasmia, as illustrated by cases 1,2 and 9 in this study and in a previous case report. ${ }^{25}$ Combined horizontal and torsional nystagmus also appears to be consistent with achiasmia as illustrated by cases 4 and 7 .

\section{Conclusions and general observations}

Certainty of the diagnosis of achiasmia can only be achieved by a combination of MRI scanning and VEPs. A number of our original sample of patients with VEP features of contralateral crossed positivity had to be excluded because the study was too noisy and/or was not reproducible on subsequent testing. It is also not possible to determine if there is complete absence of decussation on the MRI scan; this would require extremely thin sections.

Despite the wide spectrum of midline congenital CNS malformations in our achiasmic patients, most function well; five of the nine patients attend mainstream schools and are not behind their age matched peers. One (case 1) participates in junior golf competitions; another (case 6) performs well in arts and crafts. Other reports corroborate our finding of a high level of functioning in these children. ${ }^{15} 2627$
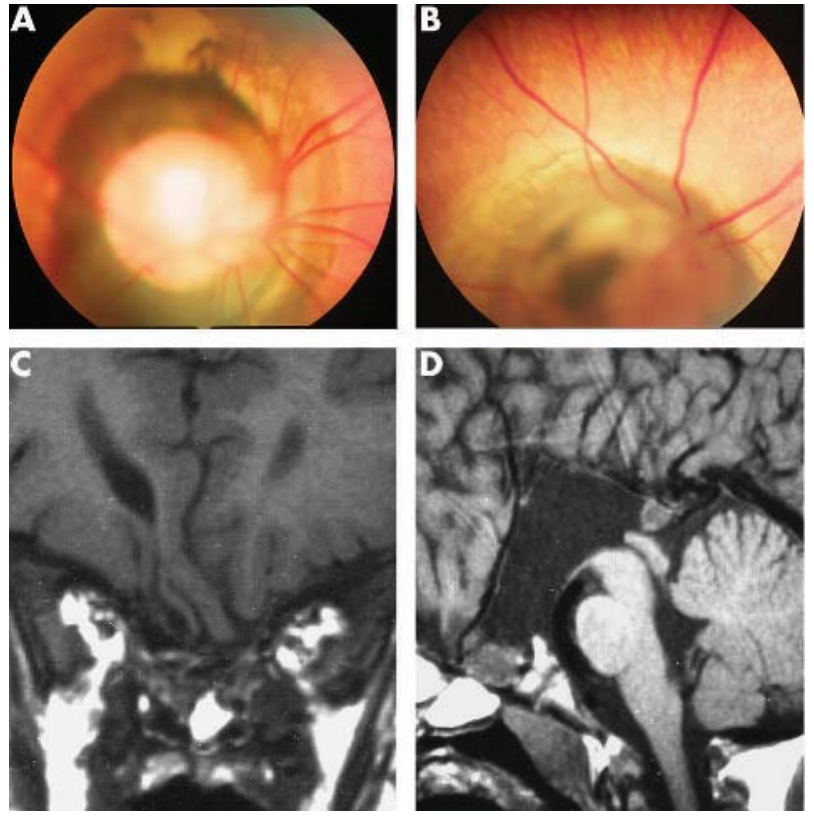

Figure 8 Case 8 (type C). Deceased boy with frontonasal dysplasia, a spheno-ethmoidal encephalocele, and agenesis of the corpus callosum. (A) Right and (B) left fundi showing posterior pole staphyloma and dysplastic discs. (C) Coronal TI weighted MRI scan through the frontal horns of the lateral ventricles showing a spheno-ethmoidal encephalocele. (D) Midline sagittal image reveals an attenuated optic chiasm and agenesis of the corpus callosum (see fig $\mathrm{IF}$ for normal corpus callosum).

Full visual fields 232744 and ophthalmoscopically normal optic discs ${ }^{25-27}$ are consistent with achiasmia, as shown by our cases 1 and 3. There does not appear to be any single pattern to the nystagmus: it may be rotary, seesaw, or purely horizontal. Subtle neurological problems may co-exist with "isolated" forms, as reported elsewhere ${ }^{1526}$ and in our cases 1 and 2 .

Achiasmia appears to be rare, but a portion of children diagnosed with "idiopathic congenital motor nystagmus" may have reduced decussation as part of the underlying abnormality-especially since VEPs and MRI scans are often not performed when the appearance of the nystagmus is "classic".

Relatively reduced decussation affects a subset of children with developmental abnormalities that include midline facial defects, basal encephaloceles, midbrain defects, pituitary and
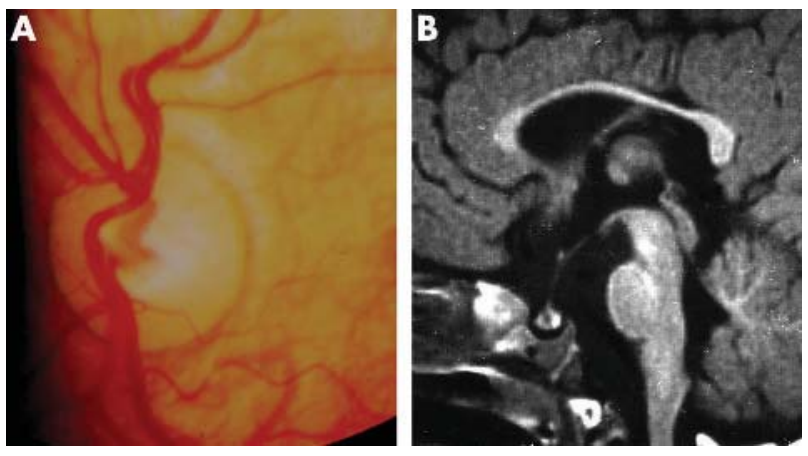

Figure 9 Case 9 (type unclassified). A 6 year old boy with an isolated small optic chiasm on the MRI scan associated with multiple facial and visceral anomalies. (A) Normal left optic disc. Photographs of the right eye had motion artefact. (B) Midline sagittal T1 weighted MRI scan showing a small optic chiasm. 
hypothalamic defects, alone or in combination. Whenever there is reason to suspect congenital chiasmal maldevelopment, VEPs, MRI scans, endocrine assessment, and visual follow up until mature are recommended.

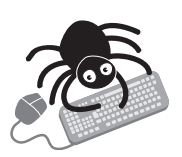

Video available on journal website at

http://bjojournals.com/supplemental

\section{Authors' affiliations}

D A Sami, D Saunders, D A Thompson, I M Russell-Eggitt, K K Nischal, R A Clement, A Liassis, D S Taylor, Visual Sciences Unit, Institute of Child Health (University College, London), London and Department of Ophthalmology, Great Ormond Street Hospital for Children, London, UK

G Jeffery, Institute of Ophthalmology, London, UK

M Dattani, Department of Biochemistry, Institute of Child Health (University College, London), London and Department of Endocrinology, Great Ormond Street Hospital for Children, London, UK

Competing interests: none declared

\section{REFERENCES}

1 Magnin M, Cooper HM, Mick G. Retinohypothalamic pathway: a breach in the law of Newton-Muller-Gudden? Brain Res 1989;488:390-7.

2 Herrera E, Brown L, Aruga J, et al. Zic2 patterns binocular vision by specifying the uncrossed retinal projection. Cell 2003;1 14:545-57

3 Apkarian P, Bour L, Barth PG. A unique achiasmatic anomaly detected in nonalbinos with misrouted retinal-fugal projections. Eur J Neurosci 1994:6:501-7.

4 McCarty JW, Demer JL, Hovis LA, et al. Ocular motility anomalies in developmental misdirection of the optic chiasm. Am J Ophthalmol 1992; 113:86-95.

5 Alvarez-Bolado G, Schwarz M, Gruss P. Pax-2 in the chiasm. Cell Tissue Res 1997;290:197-200

6 Torres M, Gomez-Pardo E, Gruss P. Pax2 contributes to inner ear patterning and optic nerve trajectory. Development 1996;122:3381-91.

7 Trousse $F$, Marti E, Gruss $P$, et al. Control of retinal ganglion cell axon growth: a new role for Sonic hedgehog. Development 2001;128:3927-36.

8 Lin L, Chan SO. Perturbation of CD44 function affects chiasmatic routing of retinal axons in brain slice preparations of the mouse retinofugal pathway. Eur J Neurosci 2003;17:2299-312.

9 Guillery RW. Developmental neurobiology: preventing midline crossings. Curr Biol 2003;13:R871-2.

10 Williams SE, Mann F, Erskine L, et al. Ephrin-B2 and EphB1 mediate retinal axon divergence at the optic chiasm. Neuron 2003;39:919-35.

11 Rasband K, Hardy M, Chien CB. Generating X: formation of the optic chiasm Neuron 2003:39:885-8.

12 Lubinsky MS. Hypothesis: septo-optic dysplasia is a vascular disruption sequence. Am J Med Genet 1997;69:235-6.

13 Margo CE, Hamed LM, Fang E, et al. Optic nerve aplasia. Arch Ophthalmol 1992;110:1610-3.

14 Apkarian P, Shallo-Hoffmann J. VEP projections in congenital nystagmus. VEP asymmetry in albinism: a comparison study. Invest Ophthalmol Vis Sci 1991;32:2653-61.

15 Apkarian P, Bour U, Barth PG, et al. Non-decussating retinal-fugal fibre syndrome. An inborn achiasmatic malformation associated with visuotopic misrouting, visual evoked potential ipsilateral asymmetry and nystagmus. Brain 1995; 118:1195-216.
16 Thompson DA, Kriss A, Chong $\mathrm{K}$ et al. Visual-evoked potential evidence of chiasmal hypoplasia. Ophthalmology 1999;106:2354-61.

17 Apkarian P, Reits D, Spekreijse H, et al. A decisive electrophysiological test for human albinism. Electroencephalogr Clin Neurophysiol 1983:55:513-31.

18 Siodell L, Sjostrom A, Abrahamsson M. Transillumination of iris and subnormal visual acuity-ocular albinism? Br J Ophthalmol 1996;80:617-23.

19 Soong F, Levin AV, Westall CA. Comparison of techniques for detecting visually evoked potential asymmetry in albinism. J AAPOS 2000;4:302-10.

20 Bouzas EA, Caruso RC, Drews-Bankiewicz MA, et al. Evoked potential analysis of visual pathways in human albinism. Ophthalmology 1994;101:309-14

21 Scott IU, Warman R, Altman N. Bilateral aplasia of the optic nerves, chiasm, and tracts in an otherwise healthy infant. Am J Ophthalmol 1997;124:409-10.

22 Waheed K, Jan W, Calver DM. Aplasia of the optic chiasm and tracts with unifocal polymicrogyria in an otherwise healthy infant. J Pediatr Ophthalmol Strabismus 2002;39:187-9.

23 Apkarian P, Bour $\amalg$. See-saw nystagmus and congenital nystagmus identified in the non-decussating retinal-fugal fiber syndrome. Strabismus 2001; 9:143-63.

24 Dell'Osso LF, Williams RW, Jacobs JB, et al. The congenital and see-saw nystagmus in the prototypical achiasma of canines: comparison to the human achiasmatic prototype. Vis Res 1998;38:1629-41.

25 Jansonius NM, van der Vliet TM, Cornelissen FW, et al. A girl without a chiasm: electrophysiologic and MRI evidence for the absence of crossing optic nerve fibers in a girl with a congenital nystagmus. J Neuroophthalmol $2001 ; 21: 26-9$.

26 Korff CM, Apkarian P, Bour $\amalg$, et al. Isolated absence of optic chiasm revealed by congenital nystagmus, MRI and VEPs. Neuropediatrics 2003;34:219-23

27 Victor JD, Apkarian P, Hirsch J, et al. Visual function and brain organization in non-decussating retinal-fugal fibre syndrome. Cereb Cortex 2000;10:2-22

28 Miller SP, Shevell MI, Patenaude Y, et al. Septo-optic dysplasia plus: a spectrum of malformations of cortical development. Neurology 2000;54:1701-3.

29 Hodgkins $\mathbf{P}$, Lees $M$, Lawson J, et al. Optic disc anomalies and frontonasal dysplasia. Br J Ophthalmol 1998;82:290-3.

30 Arnott EJ, Miller SJ. See saw nystagmus. Trans Ophthalmol Soc UK 1970;90:491-6.

31 Hassan A, Crompton JL, Sandhu A. Traumatic chiasmal syndrome: a series of 19 patients. Clin Exp Ophthalmol 2002;30:273-80.

32 Heinz GW, Nunery WR, Grossman CB. Traumatic chiasmal syndrome associated with midline basilar skull fractures. Am J Ophthalmol 1994; 117:90-6.

33 Williams RW, Hogan D, Garraghty PE. Target recognition and visual maps in the thalamus of achiasmatic dogs. Nature 1994;367:637-9.

34 Hogan D, Williams RW. Analysis of the retinas and optic nerves of achiasmatic Belgian sheepdogs. J Comp Neurol 2004;352:367-80.

35 Maddox EE. See-saw nystagmus with bitemporal hemianopia. Proc $R$ Soc Med 1914;7:12-3.

36 Rucker CW. Seesaw nystagmus associated with choroiditis and positive neuralization test for toxoplasma. Arch Ophthalmol 1946;35:301-2.

37 Jensen OA. Seesaw nystagmus. Br J Ophthalmol 1959;43:225-9.

38 Halmagyi GM, Hoyt WF. See-saw nystagmus due to unilateral mesodiencephalic lesion. J Clin Neuroophthalmol 1991;11:79-84.

39 Halmagyi GM, Aw ST, Dehaene I, et al. Jerk-waveform see-saw nystagmus due to unilateral meso-diencephalic lesion. Brain 1994;117:789-803.

40 Sparks DL. The brainstem control of saccadic eye movements. Nat Rev Neurosci 2002;3:952-64

41 Arnott EJ. Vertical see-saw nystagmus. Trans Ophthalmol Soc UK 1964:84:251-7.

42 Unsold R, Ostertag C. Nystagmus in suprasellar tumors: recent advances in diagnosis and therapy. Strabismus 2002;10:173-7.

43 Dell'Osso LF, Daroff RB. Two additional scenarios for see-saw nystagmus: achiasma and hemichiasma. J Neuroophthalmol 1998;18:112-3.

44 Apkarian P. Chiasmal crossing defects in disorders of binocular vision. Eye $1996 ; 10: 222-32$ 


\section{PostScript}

LETTERS
Primary nasolacrimal duct
malignant mucosal melanoma
Primary nasolacrimal duct malignacy is rare.
Only a few tumours have been reported
originating from this location including
lymphoma, Kaposi's sarcoma, adenocarci-
noma, angiofibroma, and squamous cell
carcinoma.
Mucosal melanoma represents $1-2 \%$ of all
melanomas, ${ }^{6}$ with $25-50 \%$ in the head and
neck-that is, upper respiratory tract, oral
cavity, and pharynx. Other sites include
urinary, female genital, and ano-rectal tracts.
These tumours are uncommon, present in the
fifth to eighth decades, have slight male
preponderance and are more common in
darker skinned individuals. Cutaneous mela-
noma presents two decades earlier and is
more common in white people and is
associated with sun exposure.

\section{Case report}

A 41 year old Asian male presented to the oculoplastic service with a 3 month history of right sided intermittent bloody tears and epistaxis. He described right simple epiphora for at least 2 years treated with a three snip procedure. Probing the right nasolacrimal system confirmed normal canaliculi and easy entry of the probe into the lacrimal sac. Irrigation demonstrated complete nasolacrimal duct block and reflux of dark bloody tears. Nasal endoscopy (rigid Hopkins nasal endoscope) revealed a greyish mass emerging from the lower end of the nasolacrimal duct into the inferior meatus (fig l).

Magnetic resonance imaging (MRI) and computed tomography (CT) scans (fig 2) demonstrated dilation of the entire length of the nasolacrimal bony canal with a soft tissue mass occupying the lumen of the nasolacrimal duct. The mass was invading the osteomeatal complex, extending into the anterior ethmoidal sinus, causing obstruction to drainage of both maxillary and frontal sinuses.

A transnasal incisional biopsy of the inferior meatus lesion was performed under local anaesthetic. Histopathological analysis of the biopsy showed sheets of epithelioid cells with prominent nucleoli and vesicular cells on a routine haematoxylin and eosin

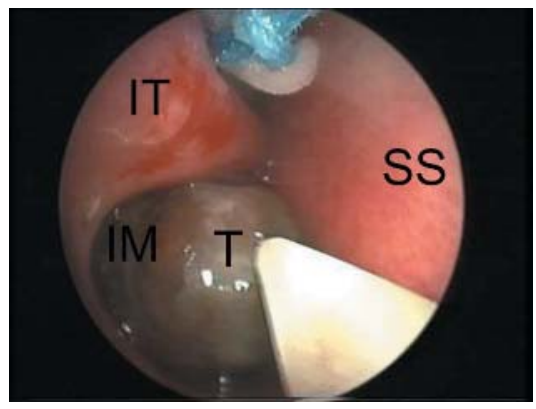

Figure 1 Endonasal view of right nasal cavity. IT, inferior turbinate; SS, septal spur; IM, inferior meatus; T, tumour.
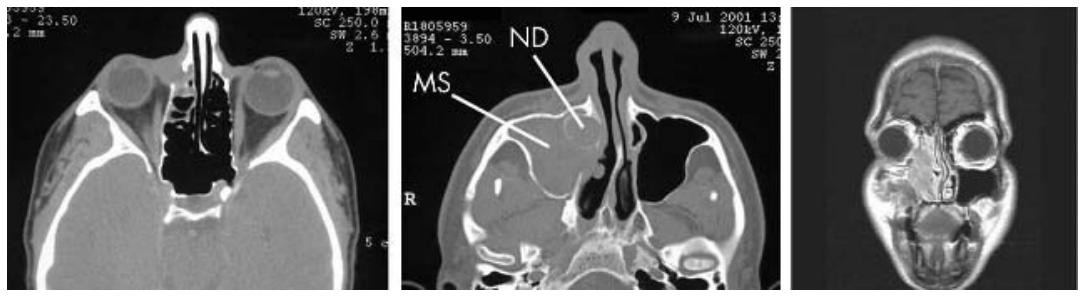

Figure 2 Imaging. (Left) CT scan head, axial view. Lesion in region of lacrimal sac. (Middle) CT scan head, axial view. ND, dilated nasolacrimal duct; with fluid in maxillary sinus (MS). (Right) MRI scan head, coronal view. Soft tissue mass extending from lacrimal sac, via nasolacrimal duct, to inferior meatus.
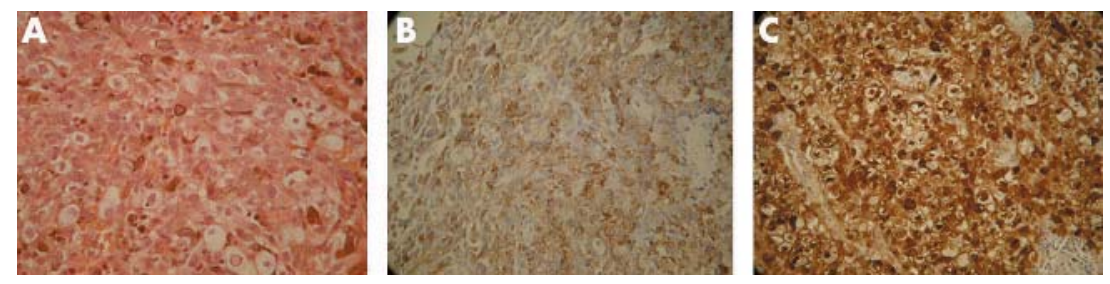

Figure 3 Histopathology slides. (A) High power $400 \times$. Haematoxylin and eosin stain showing epithelioid cells and vesicular cells and pigment. (B) Medium power $200 \times$. HMB-45 stain, positive for melanocytes. (C) High power $400 \times$. Strongly positive S-100 protein immunohistochemical stain.

stain (fig 3). Although the lesion was pale, pigment was visible on the haematoxylin and eosin stain, suggestive of melanoma. Immunohistochemical studies were positive for immunological markers HMB45 and S100 protein, confirming a diagnosis of melanoma.

No regional lymphadenopathy was present and PET (positron emission tomography) scan excluded the presence of metastases.

Wide local cranio-facial-orbital resection of the tumour was performed, via a lateral rhinotomy approach (fig 4). The nasolacrimal duct, part of the lateral wall of the nose, the lacrimal sac, distal upper and lower canaliculi, and inferomedial orbital fat were excised. Tumour extended into the maxilla but not into the lacrimal sac. Peroperative frozen sections from the excision margins, including orbital fat, demonstrated clearance of tumour. This allowed preservation of the eye.

Adjunctive therapy was given to limit local recurrence and distant spread. The patient received 20 sessions of radiotherapy (50 Gy) to the right maxillary antrum, and also immunological therapy (vaccination with autologous dendritic cells pulsed with allo-

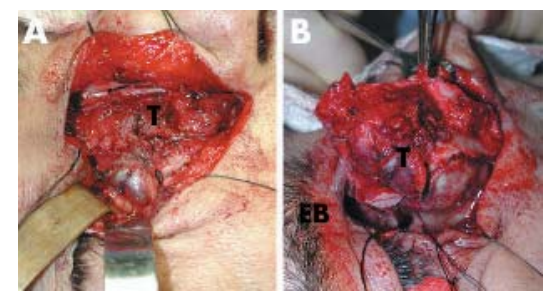

Figure 4 Wide local excision of malignant mucosal melanoma. T, tumour; EB, eyebrow. genic tumour lysate, and whole body hyperthermia accompanied by low dose interferon).

Three years after presentation there was no local recurrence of tumour. Unfortunately, the patient developed bone pain and CT scan revealed metastatic spread to the right acetabulum and T8, T9, and T11 vertebrae with localised spinal cord compression. He underwent radiotherapy to the right acetabulum and spine. The patient died approximately 6 months later.

\section{Comment}

Nasolacrimal duct primary mucosal melanoma is previously unreported. The closest relations are lacrimal sac melanoma (5\% of lacrimal sac tumours $)^{78}$ and sinonasal mucosal melanoma $(5 \%$ of all sinonasal malignacy). ${ }^{69}$

Lacrimal sac melanoma can present with epiphora, bloody tears, and epistaxis. Sinonasal melanoma can present with nasal obstruction and epistaxis. Orbital extension causes proptosis and diplopia. Both lacrimal sac melanoma and sinonasal melanoma are insidious in onset with poor visibility leading to late presentation.

Standard treatment of primary sinonasal melanoma is radical wide local surgical excision. Local recurrence can occur and the very vascular nature of mucosal tissue makes regional and distant metastases common, often accompanying late presentation. Postsurgical radiotherapy may prevent local recurrence, but is unlikely to prevent distant metastases. ${ }^{10}$ Other adjunctive treatments are not clinically proved to be beneficial. Chemotherapy has no positive effect, and newer immunological treatments are still under investigation. 
Sinonasal mucosal melanoma has a high mortality rate, with 5 year survival between 10-50\%. ${ }^{6}$ Lacrimal sac melanoma has a similar prognosis. ${ }^{78}$

This case demonstrates the importance of thorough clinical examination (including nasal endoscopy) and imaging in patients presenting with epiphora, bloody tears, and/ or epistaxis. Delay in detection and treatment may be fatal.

A M Lewis Western Eye Hospital, London, UK

P M Clarke

Charing Cross Hospital and Royal Marsden Hospital, London, UK

J M Olver

Western Eye Hospital, London, UK

Correspondence to: J M Olver, Oculoplastic and Orbital Service, The Western Eye Hospital, Marylebone Road London NW1 5YE, UK; janeolver@

aol.com

doi: $10.1136 /$ bjo. 2005.073239

Accepted for publication 24 July 2005

Competing interests: none declared.

\section{References}

1 Yip CC, Bartley GB, Haberman TM, et al. Involvement of the lacrimal drainage system by leukaemia or lymphoma. Ophthal Plast Reconstr Surg 2002; 18:242-6.

2 Khan MA, Dhillon B. Epiphora due to Kaposi's sarcoma of the nasolacrimal duct. Br J Ophthalmol 1999:83:501-2.

3 Baredes S, Ludwin DB, Troublefield YL, et al. Adenocarcinoma ex-pleomorphic adenoma of the lacrimal sac and nasolacrimal duct: a case report. Laryngoscope 2003;113:940-2.

4 Yazici B, Setzen G, Meyer DR, et al. Giant cell angiofibroma of the nasolacrimal duct. Ophthal Plast Reconstr Surg 2001;17:202-6.

5 Spira R, Mondshine R. Demonstration of nasolacrimal duct carcinoma by computed tomography. Ophthal Plast Reconstr Surg 1986;2:159-61.

6 Batsakis JG, Suarez P. Mucosal melanomas: a review. Adv Anat Pathol 2000;7:167-80.

7 Pe'er JJ, Stefanysyn M, Hidayat AA. Nonepithelial tumours of the lacrimal sac. Am J Ophthalmol 1994;1 18:650-8.

8 Stefanysyn MA, Hidayat AA, Pe'er JJ, et al. Lacrimal sac tumours. Ophthalmic Plast Reconstr Surg 1994;10:169-84.

9 Lengyel E, Gilde K, Remenar E, et al. Malignant mucosal melanoma of the head and neck- a review. Pathol Oncol Res 2003;9:7-12.

10 Owens JM, Roberts DB, Myers JN. The role of postoperative adjuvant radiation therapy in the treatment of mucosal melanomas of the head and neck region. Arch Otolaryngol Head Neck Surg 2003; 129:864-8.

\section{Glycosylation type Ic disorder: idiopathic intracranial hypertension and retinal degeneration}

We report a young woman with type Ic congenital disorder of glycosylation (CDG) with new clinical features of idiopathic intracranial hypertension, retinal degeneration, and novel mutations of ALG6. Patients with known or suspected CDG should receive a full ophthalmic examination including dilated fundus examination and electroretinography. metabolic disorders. The two major subgroups are type I, caused by dysfunction of glycosylated protein assembly, and type II, caused by abnormal processing of glycosylated protein end products after assembly. ${ }^{1}$ Patients with type Ic (OMIM \#603147) have mental retardation, axial hypotonia, very low factor XI, and seizures; the gene defect in $\alpha$ l,3-glucosyltransferase (human homologue of ALG6;OMIM *604566) encodes an enzyme that catalyses the transfer of the first glucose residue to the lipid linked oligosaccharide precursor for N-linked glycosylation. The reported ophthalmic manifestations of type I CDG are summarised in table I. We report a case of type Ic congenital disorder of glycosylation with new clinical features of idiopathic intracranial hypertension, retinal degeneration and novel mutations of ALG6.

\section{Case report}

Our patient, with non-consanguineous parents, was noted at birth to have incomplete digits on her hands and feet. She had episodes of apnoea early in life and the onset of seizures at age 20 months. Delayed physical and developmental milestones were evident early. Levels of follicle stimulating hormone and luteinising hormone were low and a diagnosis of polycystic ovarian disease was made. She underwent esotropia surgery at age 4 years and at 19 years developed thrombosis of the superficial femoral vein. Coagulation factor studies revealed very low factor XI levels. Isoelectric focusing of serum transferrin was suggestive of a congenital disorder of glycosylation. Sequencing of the ALG6 gene showed a novel three base deletion (897-899 delATT) and an intronic splice site mutation (IVS7+2T $>\mathrm{G}){ }^{2}$

The patient was obese without signs of abnormal fat distribution. She blinked to light and no strabismus was identified by corneal light reflex. Further ocular examination was not feasible. On examination under anaesthesia at age 20 years, the anterior segment was normal. Dilated ophthalmoscopy showed bilateral optic nerve pallor with elevation of each nerve, diffuse retinal pigment epithelial granularity most notable in the macula, and attenuated retinal vessels (fig 1).

Electroretinography revealed prolonged implicit times on scotopic and photopic functions. Because of the elevated optic nerve heads, head magnetic resonance imaging was performed and was normal; lumbar puncture revealed an elevated opening pressure of $350 \mathrm{~mm} \mathrm{H}_{2} \mathrm{O}\left(\mathrm{nl} 70-180 \mathrm{~mm} \mathrm{H}_{2} \mathrm{O}\right)$, a glucose of $50 \mathrm{mg} / \mathrm{dl}(\mathrm{nl} 50-75 \mathrm{mg} / \mathrm{dl}$ ), and a protein of $44 \mathrm{mg} / \mathrm{dl}$ (nl 15-45 mg/dl) without white blood cells. A diagnosis of idiopathic intracranial hypertension was made.

\section{Comment}

Isoelectric focusing of serum transferrin is the most common screening technique for
CDG is a rare group of autosomal recessive

types I and II CDG. ${ }^{1}$ Many congenital disorders of glycosylation have been identified based on mutational and enzyme analyses. Type I congenital disorders of glycosylation are caused by reduced functions of the genes for the assembly and processing pathways of $\mathrm{N}$-glycosylation; a decrease in anodal fractions and an increase of disialotransferrin and asialotransferrin are suggestive of the diagnosis.

Ophthalmic features of the most common congenital disorder of glycosylation, type Ia (OMIM \#2I2065) include myopia, attenuated retinal vessels, bone spicules, esotropia, and nyctalopia'; this disease subtype is caused by a deficiency of phosphomanomutase (OMIM \#212065) encoded by phosphomannomutase-2 (PMM2; OMIM *601785) gene. In CDG type Ic, much less common, a homozygous amino acid substitution, A333V substitution, in the gene encoding $\alpha 1,3$ glucosyltransferase is the most common mutation. ${ }^{4}$ There is no known biochemical link between CDG and idiopathic intracranial hypertension; the association in our patient may be coincidental. Grunwald and colleagues $^{5}$ found strabismus to be present in all eight patients with CDG type Ic; neither idiopathic intracranial hypertension nor retinal abnormalities were reported.

The developmental delay evident in our patient was severe. She possessed simple communication skills limiting her ability to complain of visual changes or symptoms of intracranial hypertention. No specific clinical presentation has been identified for the CDG group of diseases. Failure to thrive, unexplained seizures, hypotonia, and developmental delays are all frequently present.

In conclusion, we report an adult patient with CDG type Ic, confirmed by identification of mutations in the ALG6 gene, and describe new systemic and ocular features including idiopathic intracranial hypertension., optic

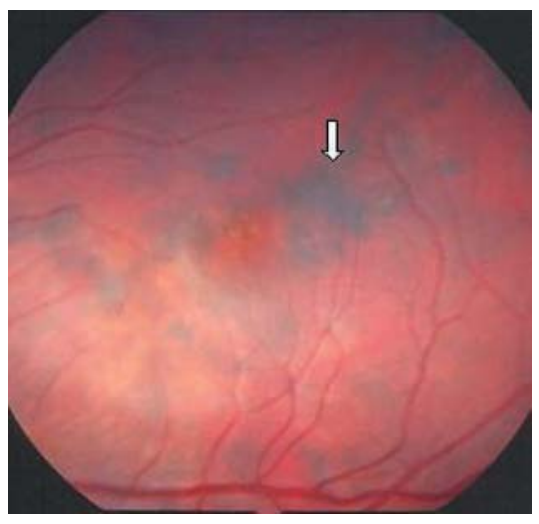

Figure 1 Left fundus showing attenuated vessels with retinal pigment cell granularity of the macula (white arrow).

Table 1 Reported ophthalmic manifestations in type I congenital disorder of glycosylation (CDG)

\begin{tabular}{llll}
\hline & CDG la & CDG lb & CDG lc \\
\hline Strabismus & + & - & + \\
Retinopathy & + & - & - \\
Optic atrophy & + & - & - \\
\hline
\end{tabular}


atrophy, and a retinal dystrophy with abnormal electroretinography.

M Y Kahook, N Mandava, J B Bateman Rocky Mountain Lions Eye Institute, Department of Ophthalmology, Denver, CO, USA

J A Thomas, J B Bateman Rocky Mountain Lions Eye Institute, Department of Pediatrics, Denver, CO, USA

Correspondence to: Malik Y Kahook, MD, 589 Franklin Blvd, Freedom, PA 15042, USA; malik. kahook@gmail.com

This is an institutional review board (IRB) exempt single case report with no identifiable patient information.

doi: 10.1136/bjo.2005.080648

Accepted for publication 1 August 2005

Supported in part by NEI Grant EY 08282 (JBB).

The authors have no interests or disclosures to report.

\section{References}

1 Jaeken J. Congenital disorders of glycosylation (CDG): it's all in it! J Inherit Metab Dis 2003;26:99-118.

2 Sun L, Eklund E, Van Hove J, et al. Clinical and molecular characterization of the first adult congenital disorder of glycosylation (CDG) type lc patient. Am J Med Genet (accepted)

3 Jensen H, Kjaergaard S, Klie F, et al. Ophthalmic manifestations of congenital disorder of glycosylation type la. Ophthal Genet 2003;24:81-8.

4 Imbach T, Burda P, Kuhnert $P$, et al. A mutation in the human ortholog of the Saccharomyces cerevisiae ALG6 gene causes carbohydratedeficient glycoprotein syndrome type-lc. Proc Nat Acad Sci USA 1999;96:6982-7.

5 Grunewald S, Imbach T, Huijben K, et al. Clinical and biochemical characteristics of congenital disorder of glycosylation type lc, the first recognized endoplasmic reticulum defect in $\mathrm{N}$ glycan synthesis. Ann Neurol 2000;47:776-81

\section{Woodhouse Sakati syndrome associated with bilateral keratoconus}

Keratoconus is a non-inflammatory degenerative corneal disease characterised by a localised region of stromal thinning spatially associated with a cone-shaped deformation of the surface. It is most commonly an isolated sporadic condition. ${ }^{1}$ Recent reports demonstrate genetic mapping to chromosomes 16q, 21q, and 18p, as well as association of HLA-A26, B40, and DR 9. ${ }^{23}$ Keratoconus has been reported in clinical contexts with 36 other multisystem disorders. ${ }^{12}$ We describe the first two cases of keratoconus in association with Woodhouse Sakati syndrome.

\section{Case report}

Two sisters (aged 14 years and 18 years) presented with history of bilateral progressive loss of vision over 8 years. Progeny of a first degree consanguineous marriage, they were the only members in the family of six siblings with a diagnosis of Woodhouse Sakati syndrome. Both sisters exhibited variable manifestations of the syndrome including hypogonadism, primary amenorrhoea, hypothyroidism, electrocardiographic abnormalities, and dysmorphic features. The elder sister also had a mild degree of mental retardation. None of their siblings or parents had eye complaints but a maternal aunt's daughter had bilateral keratoconus.

Ophthalmic evaluation of the elder sister revealed uncorrected visual acuity (UCVA) of $20 / 200$ in both eyes. Her refraction was -19.0 $-8.0 \times 120$ in the right eye and -9.0 $-3.75 \times 165$ in the left eye. Spectacles improved only left eye vision slightly to 20/ 160. Slit lamp biomicroscopy showed bilateral central corneal protrusion and stromal thinning at the apex (fig lA). Keratometry was71.00/63.00@68 in the right eye and $53.00 / 49.50 @ 135$ in the left eye. Hard contact lens fitting failed and surgical intervention was not conducted.

Ophthalmic evaluation of the younger sister revealed UCVA of 20/40 in the right eye and $20 / 160$ in the left eye, which improved to $20 / 80$ with spectacles. Slit lamp biomicroscopy showed similar findings to her sister (fig 1B). Keratometry was 36.6 D/54.1 D@170 in the right eye and 49.2 D/56.6 D@ 48 in the left eye. She developed corneal hydrops in the left eye and contact lens fitting failed. Because of central corneal scarring and progressive deterioration of her left eye vision, she underwent penetrating keratoplasty (fig lC). Fourteen months postoperatively, UCVA was 20/50, improving to 20/30 with pin hole

\section{Comment}

Woodhouse Sakati syndrome (MIM 241080) is an extremely rare genetically determined autosomal recessive disorder. It was first described in two Saudi Arabian families, ${ }^{4}$ and later reported in a single Turkish family. ${ }^{5}$ Table 1 presents manifestations of the syndrome. $^{4}$

We report a new association in our two cases. Such concurrence of early keratoconus and the syndrome raises the possibility of a genetic linkage, although a chance association cannot be excluded.

On one hand, either chromosomal rearrangements such as chromosome 7, 11 translocation or genetically determined syndromes such as this syndrome should be considered in cases where keratoconus is present during childhood. ${ }^{6}$ That may explain the early presentation of keratoconus in our cases. An additional factor is that keratoconus tends to be more prevalent and diagnosed at a younger age in Asians than in white people.

On the other hand, familial keratoconus in our cases cannot be excluded because of the presence of keratoconus in a single relative and parental consanguinity. Positive family history has been reported in $6 \%$ to $10 \%$ of keratoconus cases and is suggested to be caused by autosomal dominant inheritance with incomplete penetrance. ${ }^{1-3}$

To the best of our knowledge, this is the first report of bilateral keratoconus in asso ciation with Woodhouse Sakati syndrome. Ophthalmologists and endocrinologists should be aware that patients with this syndrome who complain of poor vision should be suspected of having keratoconus once other more common conditions are ruled out.

S A Al-Swailem, A A Al-Assiri, A A Al-Torbak Anterior Segment Division, Department of Ophthalmology, King Khaled Eye Specialist Hospital, Riyadh, Kingdom of Saudi Arabia

Correspondence to: Samar A Al-Swailem, MD Anterior Segment Division, King Khaled Eye Specialist Hospital, PO Box 7191, Riyadh 11462, Kingdom of Saudi Arabia; angelofsa@yahoo.com

doi: 10.1136/bjo.2005.080101 Accepted for publication 12 August 2005

Competing interests: none declared

\section{References}

1 Rabinowitz YS. Keratoconus. Surv Ophthalmol 1998:42:297-319.

2 Tyynismaa $\mathbf{H}$, Sistonen P, Tuupanen S, et al. A locus for autosomal dominant keratoconus: linkage to $16 q 22.3-q 23.1$ in Finnish families. Invest Ophthalmol Vis Sci 2002;43:3160-4.
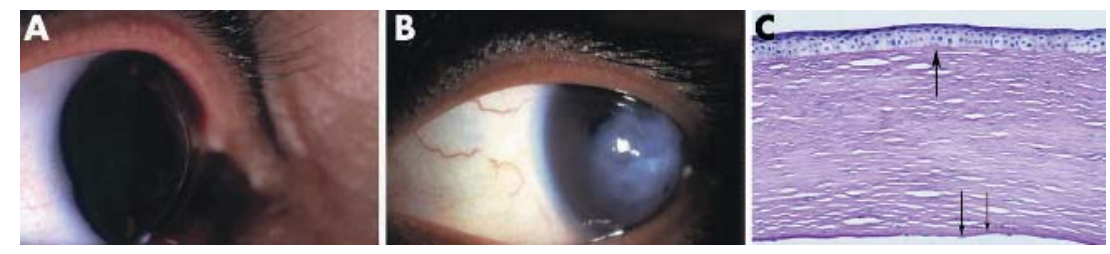

Figure 1 Features of keratoconus are seen. (A) Slit lamp biomicoscopy of the right cornea in the elder patient, showing advanced cone deformation and deep Descemet's membrane scarring. (B) Slit lamp biomicoscopy of the left cornea in the younger patient, showing dense central scarring following hydrops attack. (C) Histopathological section of left corneal button illustrating the fragmentation of Bowman's layer (large arrow) and large break in Descemet's membrane (small arrows) (periodic acid Schiff stain, $\times 200$ ).

Table 1 Variable manifestations in the nine reported patients with Woodhouse Sakati syndrome

Delayed psychomotor development

Variable degree of mental retardation (very frequent sign)

Alopecia (very frequent sign), spare/absent scalp and eyebrow hair (frequent sign), dysarthria Dysmorphic features: high forehead, flat occiput, triangular face, prominent nasal root, hypertelorism, and down-slanting palpebral fissures.

Hyper/hypogonadotrophic hypogonadism and late puberty (very frequent sign)

Sensorineural deafness (very frequent sign)

Electrocardiographic abnormalities and insulin dependent diabetes mellitus (very frequent signs)

No ocular manifestations 
3 Adachi $W$, Mitsuishi $Y$, Terai $K$, et al. The association of HLA with young-onset keratoconus in Japan. Am J Ophthalmol 2002;133:557-9.

4 Woodhouse NJ, Sakati NA. A syndrome of hypogonadisim, alopecia, diabetes mellitus, mental retardation, deafness and ECG abnormalities. J Med Genet 1983;20:216-19.

5 Gul D, Ozata M, Mergen H, et al. Woodhouse and Sakati syndrome (MIM 241080) report of a new patient. Clin Dysmorph 2000;9:123-5.

6 Morrison DA, Rosser EM, Claove C. Keratoconus associated with a chromosome 7, 11 translocation. Eye 2001;15:556-7.

\section{Retinal ischaemia in type 1 neurofibromatosis}

Systemic occlusive arteriopathy associated with type 1 neurofibromatosis (NF-1) has been well described in the aortic and cerebral vasculature $^{1}$; however, it is poorly documented in the retinal vasculature with, to our knowledge, only three reported patients whose retinal vasculopathy was diagnosed at a later sequelae stage. ${ }^{2-4}$ We report the case of a young woman with NF-1 who presented with acute macular ischaemia combined with diffuse retinal arterial occlusive disease.

\section{Case report}

A 26 year old woman with NF-1 presented with a sudden painless loss of vision in her left eye. Visual acuity was counting fingers left eye and 20/20 right eye. NF-1 had previously been diagnosed on the basis of multiple café au lait spots, plexiform neurofibromas, and a paternal history of NF-1. Left fundus examination revealed confluent cottonwool spots in the perifoveal area, focal dilatations and narrowings of retinal venules, and progressive enlargement of retinal arterioles towards the periphery. The right fundus showed only peripapillary myelinated nerve fibres (fig l).

Fluorescein angiography (FA) of the left eye showed no delayed perfusion in the choriocapillaris or central retinal artery, but a delayed retinal arteriovenous filling time. It revealed occlusion of macular arterioles, retinal arteriovenous communications in the mid-periphery, and a relatively well perfused retinal periphery (fig 2 ).

Cerebral and cervical magnetic resonance imaging and colour Doppler ultrasonography showed no vascular flow abnormalities. Internal medical examination and laboratory results excluded other diseases associated with retinal microvasculopathies.

One month after the initial examination, all the cottonwool spots disappeared, and sheathing appeared in a few veins. FA showed worsening of the retinal arteriolar occlusions in the mid-periphery (fig 2). A panretinal photocoagulation was subsequently performed. At 2 year follow up, left visual acuity remained unchanged, and the patient did not exhibit any preretinal fibrovascular proliferation.

\section{Comment}

To our knowledge, only three cases of retinal vascular occlusion in patients with NF-1 have been previously reported. All cases were diagnosed at a later sequelae stage. Moadel et $a l^{2}$ and Kadoi et al, ${ }^{3}$ respectively, reported the cases of a child who presented with an unilateral amblyopia, and a young woman with a history of unilateral poor vision. They both presented with diffuse sheathing of retinal vessels, retinal arteriovenous

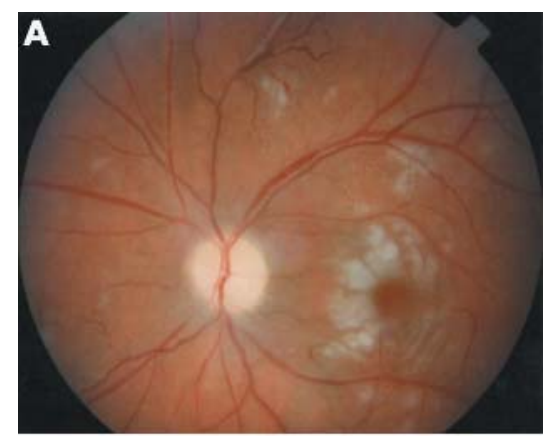

communications, and avascular peripheral retina with fibroglial proliferation. Thölen et $\mathrm{al}^{4}$ described a young man whose routine eye examination showed narrowing of a superotemporal retinal arteriole with irregular diameter of the corresponding vein, fibroglial proliferation, and arteriovenous communications. These authors suggested the possibility of either a primary occlusion of a retinal arterial or venous branch or alterations of vessel development. In contrast with other reported cases, our patient presented with acute unilateral occlusion of macular arterioles, combined with diffuse retinal arterial occlusive disease, in adulthood. Panretinal photocoagulation may have prevented fibroglial proliferation which was described in previous reported cases. Recent reports suggest that pathogenesis of NF-1 vasculopathy may result from dysfunction of neurofibromin, the NF-l gene product, in vessel endothelial and smooth muscle cells. ${ }^{5}$

Our case shows that NF-1 related occlusive retinal arteriopathy may suddenly appear during adulthood and should be considered in patients with NF-1 or in young adults with retinal vascular occlusive disease and unknown NF-1.

\section{A Lecleire-Collet, S Y Cohen, C Vignal,}

A Gaudric

Figure 1 Fundus photographs of the left and the right eyes at presentation. (A) Colour fundus photograph of the left eye showing large confluent cottonwool spots in the perifoveal area. (B) Colour fundus photograph of the right eye showing peripapillary myelinated nerve fibres. (C) Red-free fundus photograph of the left eye. Upper periphery showing focal dilatations and narrowings of retinal veinules, and capillary rarefaction. Retinal arteriovenous communications are also present (arrows).
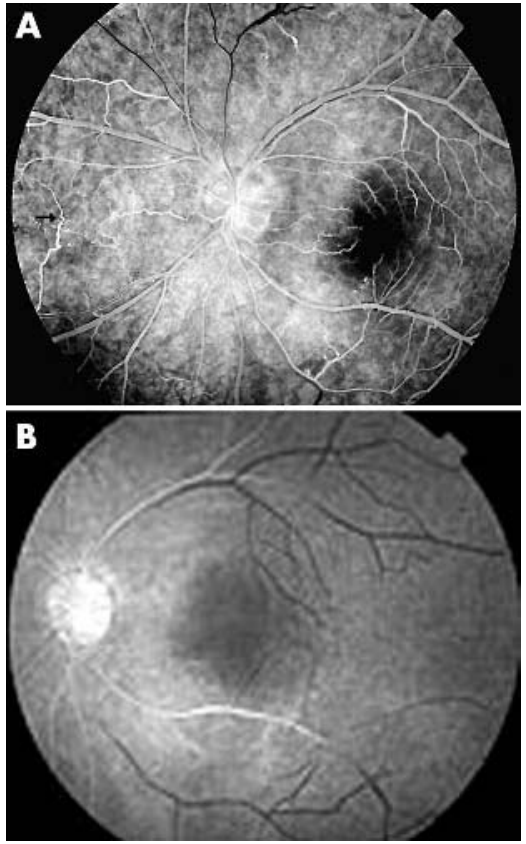

Figure 2 Fluorescein retinal angiography of the left eye, 40 seconds after dye injection, at presentation (A) and 1 month later (B). (A) Occlusion of macular arterioles and retinal arteriovenous communications are visible (black arrow). (B) Retinal arteriolar occlusions have worsened in the temporal periphery.
Department of Ophthalmology, Hôpital Lariboisière, Assistance Publique-Hôpitaux de Paris and Université Paris 7, France

A Lecleire-Collet

Department of Ophthalmology, Rouen University Hospital Charles Nicolle, Rouen, France

S Y Cohen, G Quentel

Centre Ophtalmologique $d^{\prime}$ Imagerie et de Laser, Paris, France

Correspondence to: Dr Salomon Y Cohen, Centre Ophtalmologique d'Imagerie et de Laser, 11 Rue Antoine Bourdelle, 75015 Paris, France; sycohen@ club-internet.fr

doi: 10.1136/bjo.2005.077701 Accepted for publication 12 August 2005

\section{References}

1 Saylor WR, Saylor DC. The vascular lesions of neurofibromatosis. Angiology 1974:25:510-19.

2 Moadel K, Yannuzzi LA, Ho AC, et al. Retinal vascular occlusive disease in a child with neurofibromatosis. Arch Ophthalmol 1994;112:1021-3.

3 Kadoi C, Nagaki Y, Hayasaka S. Unilateral Japanese woman with neurofibromatosis- 1 . Retina 2003;23:541-3.

4 Thölen AM, Messmer EP, Landau K. Peripheral retinal vascular occlusive disorder in a young patient with neurofibromatosis 1 . Retina

5 Hamilton SJ, Friedman JM. Insights into the pathogenesis of neurofibromatosis 1 vasculopathy. Clin Genet 2000;58:341-4.

\section{Are biometric parameters a risk} factor for idiopathic macular hole formation? Results of a matched case-control series

Recognised risk factors for the formation of idiopathic full thickness macular holes (IFTMH) include age, female, sex, and high myopia. ${ }^{12}$ However, we noticed that patients with IFTMH within our population, tended to have shorter than normal axial lengths. An age and sex matched case-control study was peripheral retinal vascular occlusion in a young 1998; 18:184-6. 
therefore performed to test this hypothesis and determine whether biometric factors may be associated with formation of IFTMH.

\section{Methods}

Consecutive patients undergoing surgery for IFTMH had age, sex, axial length in millimetres $(\mathrm{mm})$, and corneal keratometry $(\mathrm{K})$ measurements in dioptres (D) recorded.

For each case three age and sex matched controls were randomly identified from a cataract surgery database (Medisoft). Biometric measurements were made in all cases and controls using the IOL-Master (Zeiss, Jena). Mean corneal curvature was calculated by averaging the two K readings.

Descriptive statistics and conditional logistic regression method for analysis of matched pair data were used to infer estimates.

\section{Results}

Thirty five consecutive cases and 105 controls were identified with a mean age of 67.3 years (35-77 years) and a female to male ratio of 24:11. The mean (SD) axial length in the cases was $22.94(0.96) \mathrm{mm}$ whereas in controls it was $23.48(1.44) \mathrm{mm}$. The axial lengths of the cases also fell within a narrower range than those of the controls (fig 1). Mean K readings in cases was $44.04 \mathrm{D}$ (range 41.87-46) and 43.44 D in controls. (range 40.56-47.92).

Evidence suggests that the longer the axia length the less the odds of being a case; odds ratio (OR) 0.67 ( $\mathrm{p}=0.036$, CI 0.47 to 0.77 ) and the higher the dioptre power of the curvature the higher the odds of being a case as opposed to a control; OR 1.50 ( $\mathrm{p}=0.02$, CI 1.07 to 2.01 )

\section{Comment}

As in previous studies our population sample demonstrates an increased risk of IFTMH in females with most cases clustering in the 60 70 year age group. ${ }^{34}$ The mean axial length in controls was also found to be similar to results in the published literature. ${ }^{56}$

Mean spherical equivalence (MSE) was measured by the Eye Disease Case Control Study Group ${ }^{7}$ and although their findings were statistically insignificant, their regression analysis found an increased likelihood of hypermetropia in the IFTMH cases. Our cases clustered in a relatively narrow range of axial lengths $(21 \mathrm{~mm}-25.31 \mathrm{~mm}$ in the cases compared to $20.64 \mathrm{~mm}-29.48 \mathrm{~mm}$ in the controls) with the maximum axial length in the cases being $25.31 \mathrm{~mm}$ (fig 1). In Japanese literature, high myopia is a prominent, recognised risk factor and in one study the overall mean MSE was -0.66 D. ${ }^{2}$ From our study it appears myopic macular holes are encountered much less frequently in a predominantly white population.

We believe the significant corneal dioptric differences found may be a result of the natural process of emmetropisation of a shorter eye, or alternatively be an independent risk factor.

IFTMH are thought to arise from retinal surface traction which in turn arises from an abnormal and incomplete posterior vitreous detachment. ${ }^{8}$ Our results suggest that eyes with shorter than average axial lengths and therefore lower volume vitreous cavity are either at increased risk of developing such incomplete and abnormal vitreous detachments or, in the presence of such an incomplete vitreous detachment, of developing a macular hole. We are not aware that shorter axial length has previously been shown to be significantly associated with IFTMH.

S P Shah

Vitreoretinal Speciality, Eye Department, St Thomas's Hospital, Lambeth Palace Road, London SEI 7EH, UK

C Bunce

Moorfields Eye Hospital, London, UK

R L Johnston

Cheltenham General Hospital Cheltenham, Sandford Road, Cheltenham GL53 7AN, UK

D A H Laidlaw

St Thomas's Hospital, Lambeth Palace Road, London SEI 7EH, UK

Correspondence to: Shaheen P Shah, MRCOphth, Ophthalmology, Vitreoretinal Speciality, Eye Department, St Thomas's Hospital, Lambeth Palace Road, London SEl 7EH, UK; shaheen_shah@hotmail.com

doi: 10.1136/bjo.2005.077008

Accepted for publication 21 August 2005

RU has a commercial and proprietary interest in the cataract database from which control data were derived.

\section{$\square$ Cases $\square$ Controls}

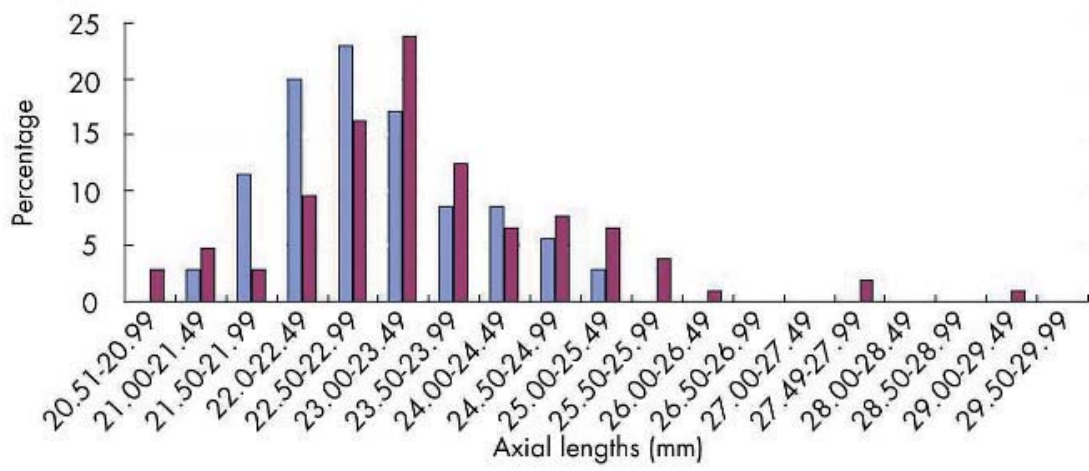

Figure 1 Axial lengths $(\mathrm{mm})$ of patients with macular holes compared with age and sex matched controls.

\section{References}

1 Evans JR, Schwartz SD, McHugh JD, et al. Systemic risk factors for idiopathic macular holes: a case-control study. Eye 1998;12(P+ 2):256-9.

2 Kumagai K, Ogino N, Demizu S, et al. Clinical features of idiopathic macular holes. Nippon Ganka Gakkai Zasshi 2000:104, 118:19-25.

3 James M, Feman SS. Macular holes. Graefes Arch Clin Exp Ophthalmol 1980;215:59-63.

$4 \mathrm{McDonnell}$ PJ, Fine SL, Hillis Al. Clinical features of idiopathic macular cysts and holes. Am J Ophthalmol 1982:93:777-86.

5 Shimmyo M, Orloff PN. Corneal thickness and axial length. Am J Ophthalmol 2005;139:553-4.

6 Gudmundsdottir $E$, Arnarsson A, Jonasson F. Five-year refractive changes in an adult population: Reykjavik Eye Study. Ophthalmology 2005; 112:672-7.

7 No authors listed. Eye disease case control study group, Risk factors for idiopathic macular holes. Am J Ophthalmol 1994;118:754-61.

8 Chauhan D, Antcliff R, Rai P, et al. Papillofoveal traction in macular hole formation: the role of optical coherence tomography. Arch Ophthalmol 2000;118:32-8.

\section{Choroiditis and exudative macular detachments in a post transplant leukaemic patient: an unusual presentation of Pneumocystis jiroveci infection}

Pneumocystis jiroveci is a commensal found in the respiratory tract of healthy individuals. It can cause infections of almost any organ in immunocompromised hosts. $P$ jiroveci choroiditis, featuring multifocal choroidal lesions, has been reported in immunocompromised patients despite prophylactic use of inhaled pentamidine. We report a post-transplant leukaemic patient whose posterior segment findings demonstrate an atypical picture of recurrent $P$ jiroveci choroiditis.

\section{Case report}

A 20 year old woman presented with a l week history of bilateral blurred vision, dyspnoea, and dry cough. Visual acuity was reduced to $6 / 36$ bilaterally with posterior subcapsular cataracts. Funduscopy disclosed multifocal, creamy-yellow choroidal lesions at both posterior poles with exudative retinal detachments at the maculae (fig 1). Optic discs and retinal vessels were normal. Fluorescein angiography showed early patchy hypofluorescence (corresponding to the choroidal lesions) and late hyperfluorescence with pooling beneath the detachments.

Three years earlier she had undergone a successful allogeneic bone marrow transplant for chronic myeloid leukaemia. Her maintenance therapy included inhaled pentamidine as prophylaxis against $P$ jiroveci infection. However, she admitted to not taking her inhaled pentamidine. Molecular genetic and radiological investigations excluded leukaemic recurrence. Chest $x$ ray showed left lung shadowing and bronchoalveolar lavage isolated $P$ jiroveci. $P$ jiroveci pneumonia with $P$ jiroveci choroiditis was diagnosed and high dose oral co-trimoxazole $7.2 \mathrm{~g} /$ day $(120 \mathrm{mg} / \mathrm{kg} /$ day) and prednisolone $60 \mathrm{mg} /$ day commenced. Within 2 weeks her respiratory and ocular symptoms improved. Visual acuities returned to $6 / 9$ and the fundal appearances resolved. She was discharged on daily oral co-trimoxazole $960 \mathrm{mg}$, prednisolone $20 \mathrm{mg}$, and inhaled pentamidine. 
Three weeks later she was readmitted with increasing dyspnoea and blurred vision. Chest $x$ ray and computed tomography findings were compatible with diffuse interstitial fibrosis in both lungs. Funduscopy revealed peripapillary choroidal lesions with disc swelling bilaterally (fig 2 ). This time the choroidal lesions were peripapillary only rather than throughout the posterior pole, with exudative detachments inferiorly. Recurrent $P$ jiroveci pneumonia and choroiditis was diagnosed and oral atovaqoune and high dose prednisolone were commenced. Within 3 weeks her fundal appearance resolved leaving only some pigmentary changes. Her discharge medication included daily oral prednisolone $40 \mathrm{mg}$, cotrimoxazole $960 \mathrm{mg}$, and inhaled pentamidine. There have been no further intraocular recurrences.

\section{Comment}

Pneumocystis jiroveci is a commensal, found in the respiratory tract of healthy individuals. It can cause infections of almost any organ in immunocompromised hosts. ${ }^{1-3} P$ jiroveci choroiditis has been reported in immunocompromised patients despite prophylactic use of inhaled pentamidine. ${ }^{45}$ The diagnosis is based on the clinical findings of multifocal yellowish circular choroidal lesions at the posterior pole. $P$ jiroveci has been found in these lesions on histological sections ${ }^{35}$ and the lesions resolve on systemic anti-pneumocystis treatment. ${ }^{4}$ However, most cases of $P$ jiroveci choroiditis are diagnosed histologically post mortem. ${ }^{36}$

Thus, the acute clinical findings may be more varied than previously described. In our patient, massive exudative retinal detachments were associated with the previously described choroidal lesions. The clinical picture varied on the second presentation, but there was complete and rapid resolution of the signs with anti-pneumocystis therapy. To the best of our knowledge, this is the first report of $P$ jiroveci choroiditis causing exudative retinal detachments. $P$ jiroveci should be considered in the differential diagnosis of susceptible patients, even if the ophthalmological findings are "atypical."

K Sabri, K Bibby Department of Ophthalmology, Leicester Royal Infirmary, Leicester LE1 5WW, UK

Correspondence to: K Sabri, Department of Ophthalmology, Leicester Royal Infirmary, Leicester LE1 5WW, UK; ksabri@yahoo.com

doi: 10.1136/bjo.2005.077479

Accepted for publication 21 August 2005

\section{References}

1 Dugel PU, Rao NA, Forster DJ, et al. Pneumocystis carinii choroiditis after long term aerosolized pentamidine therapy. Am J Ophthalmol 1990;110:113-17.

2 Whitcup SM, Fenton RM, Pluda JM, et al. Pneumocystis carinii and Mycobacterium aviumintracellulare infection of the choroid. Retina 1992;12:331-5.

3 Northfelt DW, Clement MJ, Safrin S Extrapulmonary pneumocystosis: clinical features in human immunodeficiency virus infection. Medicine 1990;69:392-8.

4 Sneed SR, Blodi CF, Berger BB, et al. Pneumocystis carinii choroiditis in patients receiving inhaled pentamidine. N Engl J Med 1990;322:936-7.

5 Rao NA, Zimmerman PL, Boyer D, et al. A clinical, histopathologic, and electron microscopic study of pneumocystis carinii choroiditis. Am J Ophthalmol 1989:107:218-28.

6 Macher A, Bardenstein D, Zimmerman L, et al. Pneumocystis carinii choroiditis in a male homosexual with AIDS and disseminated pulmonary and extrapulmonary $\mathrm{P}$ carinii infection. N Engl J Med 1987;316:1092.

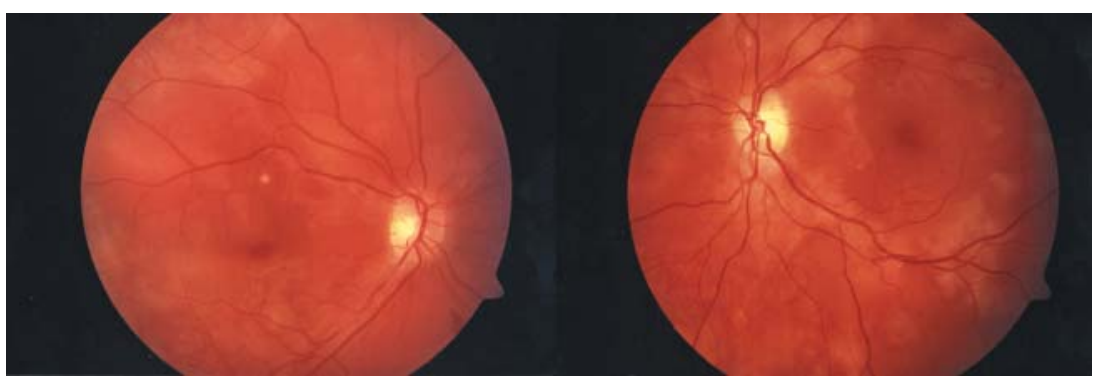

Figure 1 Multifocal, creamy-yellow choroidal lesions at both posterior poles with massive exudative retinal detachments at the maculae.

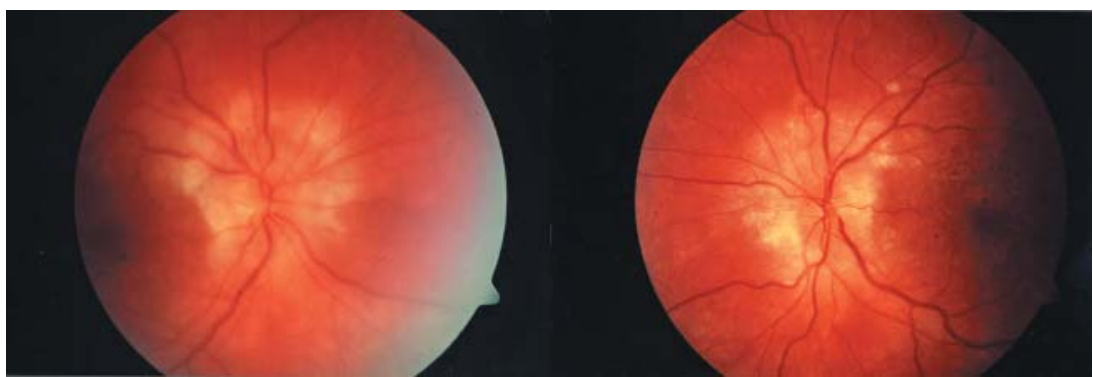

Figure 2 peripapillary choroidal lesions with disc swelling.

Prothrombotic and

atherosclerotic risk factors lack significance in NAION patients harbouring mitochondrial DNA mutations

We recently reported that a group of patients with non-arteritic anterior ischaemic optic neuropathy (NAION) had an increased prevalence of potentially pathological mitochondrial DNA (mtDNA) mutations, implying a link between mitochondrial disease and this optic neuropathy. ${ }^{1}$ We decided to investigate the association of other risk factors for NAION in these same patients.

\section{Case reports}

NAION patients were genotyped for the presence of prothrombotic polymorphisms that have been reported in association with NAION, ${ }^{2}{ }^{3}$ including factor II G20210A prothrombin variant, factor $\mathrm{V}$ Leiden G1691A variant, MTHFR C677T and Al298C variants, platelet glycoprotein receptor IIIa $\left(\mathrm{PI}^{\mathrm{A} 2}\right)$ allele, and apolipoprotein E (4) allele, as described previously. ${ }^{4-8}$ These reports included large control groups that were ethnically matched to our NAION patients and that had been queried regarding the presence of atherosclerotic risk factors. Controls older than 50 years were selected for comparison with NAION patients.

Table 1 shows that the prevalence rates for prothrombotic variants among NAION patients did not differ from controls. Reported prevalence of diabetes, hypertension, and hyperlipidaemia was relatively high in NAION patients but was also not significantly different from controls.

\section{Comment}

The lack of a significant association between NAION patients and controls in relation to thrombophilic genetics markers has been reported before, ${ }^{9}$ and the role of these factors remains uncertain. More surprising is the lack of a statistical association with atherosclerotic risk factors. For example, in our group of NAION patients, $68 \%$ were diabetic, but this figure did not differ significantly from the prevalence of more than $50 \%$ in well matched controls. This observation reflects the high, and rising, frequency of diabetes and other atherosclerotic risk factors in the developing world.

A few qualifications are appropriate. NAION patients were a relatively small group of Middle Eastern Arabs, and it is possible that a larger group would have yielded statistically significant results or that the observations reported here are specific to this genetically homogeneous population. Atherosclerotic risk factors were assessed by individual report from patients and controls, and the actual prevalence of these disorders may be different from that recognised. Finally, other risk factors, such as homocysteine levels, nocturnal hypotension, or environmental factors ${ }^{10}$ were not consistently investigated.

Nevertheless, the fact that the occurrence of NAION cannot be easily explained by the presence of prothrombotic or atherosclerotic risk factors shifts focus to the possibility that mitochondrial abnormalities may be important in the development of NAION. Based on these observations, testing for mitochondrial abnormalities may be warranted in NAION patients, especially the ones without a 
Table 1 Comparison of risk factors in NAION patients and controls

\begin{tabular}{|c|c|c|c|c|c|c|}
\hline Risk factor & & $\begin{array}{l}\text { NAION } \\
\text { patients }\end{array}$ & Controls & Odds ratio & $95 \% \mathrm{Cl}$ & p Value \\
\hline Apo E4 & Homo & $0 / 19$ & $0 / 593$ & 31.2 & 0.60 to 1615.3 & 1 \\
\hline \multirow[t]{2}{*}{ Factor II G20210A } & Homo & $0 / 19$ & $0 / 593$ & 31.2 & 0.60 to 1615.3 & 1 \\
\hline & Hetero & $0 / 19$ & $10 / 593$ & 0 & 0.00 to 17.52 & 1 \\
\hline \multirow[t]{2}{*}{ Factor V G1691A } & Homo & $0 / 19$ & $0 / 200$ & 10.5 & 0.20 to 545.6 & 1 \\
\hline & Hetero & $0 / 19$ & $5 / 200$ & 0 & 0.00 to 13.10 & 1 \\
\hline \multirow{2}{*}{ MTHFR C677T } & Homo & $0 / 19$ & $12 / 625$ & 0 & 0.00 to 15.06 & 1 \\
\hline & Hetero & $4 / 19$ & $161 / 625$ & 0.77 & 0.21 to 2.52 & 0.79 \\
\hline \multirow[t]{2}{*}{ MTHFR A1298C } & Homo & $0 / 19$ & $57 / 625$ & 0 & 0.00 to 2.71 & 0.39 \\
\hline & Hetero & $7 / 19$ & $322 / 625$ & 0.55 & 0.19 to 1.52 & 0.30 \\
\hline \multirow[t]{2}{*}{$\mathrm{Pl}^{\mathrm{A} 2}$ allele } & Homo & $0 / 19$ & $12 / 509$ & 0 & 0.00 to 12.22 & 1 \\
\hline & Hetero & $3 / 19$ & $137 / 509$ & 0.51 & $0.12-1.89$ & 0.41 \\
\hline Age, mean (SD) & - & $58.8(8.5)$ & $57.1(4.2)$ & - & - & 0.40 \\
\hline $\operatorname{Sex}(M: F)$ & - & $14: 5$ & $351: 160$ & 1.28 & 0.42 to 4.13 & 0.64 \\
\hline Diabetes & - & $13 / 19$ & $256 / 511$ & 2.16 & 0.75 to 6.47 & 0.18 \\
\hline Hypertension & - & $10 / 19$ & $209 / 511$ & 1.61 & 0.59 to 4.38 & 0.43 \\
\hline Hyperlipidaemia & - & $2 / 19$ & $59 / 511$ & 0.68 & 0.11 to 3.17 & 1 \\
\hline CAD & - & $1 / 19$ & $27 / 511$ & 0.55 & 0.03 to 4.03 & 1 \\
\hline NS mtDNA changes & - & $14 / 19$ & $11 / 100$ & 22.6 & 6.03 to 91.07 & $<0.001$ \\
\hline
\end{tabular}

NAION, non-arteritic ischaemic optic neuropathy; CAD, coronary artery disease; NS mtDNA changes, non-synonymous (changing an amino acid in the resultant protein) mitochondrial DNA nucleotide change; Homo, homozygous; Hetero, heterozygous. Diabetes, hypertension, hyperlipidaemia, and CAD were assessed by patient report both from NAION patients and from controls. Controls previously reported for mtDNA changes and for atherosclerotic and prothrombotic risk factors (see text). Odds ratio and $p$ values compare prevalence of different risk factors in NAION patients to controls.

medical or family history of a thrombotic or vascular event.

K K Abu-Amero

Mitochondrial Research Laboratory, Department of Genetics, King Faisal Specialist Hospital and Research Centre, Riyadh, Kingdom of Saudi Arabia

T M Bosley

Neuro-ophthalmology Service, King Khaled Eye Specialist Hospital, Riyadh, Kingdom of Saudi Arabia

Correspondence to: Dr Khaled K Abu-Amero, Mitochondrial Research Laboratory, Department of Genetics, King Faisal Specialist Hospital and Research Center (MBC \# 03), PO Box 3354, Riyadh 11211 ,

Kingdom of Saudi Arabia; kamero@kfshrc.edu.sa

doi: 10.1136/bjo.2005.078071

Accepted for publication 9 July 2005

\section{References}

Bosley TM, Abu-Amero KK, Ozand PT. Mitochondrial DNA nucleotide changes in nonarteritic ischemic optic neuropathy. Neurology 2004;63:1305-8.

2 Nagy V, Facsko A, Takacs L, et al. Activated protein $\mathrm{C}$ resistance in anterior ischaemic optic neuropathy. Acta Ophthalmol Scand 2004;82:140-3.

3 Glueck CJ, Wang $\mathrm{P}$, Bell $\mathrm{H}$, et al. Nonarteritic anterior ischemic optic neuropathy: associations with homozygosity for the C677T methylenetetrahydrofolate reductase mutation. J Lab Clin Med 2004;143:184-92.

4 Abu-Amero KK, Wyngaard CA, Kambouris M, et al. Prevalence of the $20210 \mathrm{G} \rightarrow \mathrm{A}$ prothrombin variant and its association with coronary artery disease in a Middle Eastern Arab population Arch Pathol Lab Med 2002;126:1087-90.

5 Abu-Amero KK, Wyngaard CA, Dzimiri N. Prevalence and role of methylenetetrahydrofolate reductase $677 \mathrm{C} \rightarrow$ T and $1298 \mathrm{~A} \rightarrow \mathrm{C}$

polymorphisms in coronary artery disease in Arabs. Arch Pathol Lab Med 2003; 127:1349-52.

6 Abu-Amero KK, Wyngaard CA, Dzimiri N. Association of the platelet glycoprotein receptor Illa (PIA I/PIA I) genotype with coronary artery disease in Arabs. Blood Coagul Fibrinolysis 2004; 15:77-9.

7 Dzimiri N, Meyer BF, Hussain SS, et al. Relevance of apolipoprotein $E$ polymorphism for coronary artery disease in the Saudi population. Arch Pathol Lab Med 1999;123:1241-5.
8 Dzimiri N, Meyer B. World distribution of factor V Leiden. Lancet 1996;347:481-2.

9 Salomon O, Huna-Baron R, Kurtz S, et al. Analysis of prothrombotic and vascular risk factors in patients with nonarteritic anterior ischemic optic neuropathy. Ophthalmology 1999; 106:739-42.

10 Hayreh SS. Risk factors in AION. Ophthalmology 2001;108:1717-18.

\section{Inflammatory cytokine of basal and reflex tears analysed by multicytokine assay}

Tear cytokine has a major role in various pathophysiological conditions of the ocular surface. So far, studies on tear cytokines have shown significant progress in providing an understanding of ocular surface diseases. ${ }^{1-3}$ The information that could be acquired from each subject, however, until recently has been severely hampered by limited sample volume and assay sensitivity. More importantly, it has become apparent that the relative balance between various cytokines and combinations of cytokines could be more important than absolute concentrations. Previous studies showed that the composition of basic and reflex tears was different, which made it more difficult to understand the ocular surface disorder correctly or to treat the patients suitably. ${ }^{4}$ Cytometric bead array (CBA) is a microparticle based flow cytometric assay that allows us to quantify multiple molecules from a very small sample. ${ }^{367}$ Using this method, we evaluated the inflammatory cytokines of basal and reflex tears from a single sample of individual eyes.

\section{Methods}

Twenty three normal volunteers (11 males and 12 females, 22-44 years of age, average 28 years) were recruited for this study. None of the subjects had signs of ocular diseases. The study was performed with the approval of the institutional review board. The basal tear samples of 10-15 $\mu \mathrm{l}$ were obtained from each eye by capillary flow, with no nasal stimulation or previous instillation of drugs or vital dyes. Each sample was collected at
5 pm. No anaesthetic drops were instilled. The samples were collected non-traumatically from the inferior meniscus. Successively, reflex tear samples were collected by inserting application sticks into a participant's nose. The amounts of six inflammatory molecules interleukin (IL)-1 $\beta$, IL-6, IL-8, IL-10, IL-12p70, and tumour necrosis factor $\alpha$ $(\mathrm{TNF}-\alpha)$, were measured by CBA (BD Biosciences, San Diego, CA, USA), according to the manufacturer's instructions. Briefly, for the tear sample and cytokine standard mixture, $10 \mu \mathrm{l}$ of sample or standard were added to $40 \mu \mathrm{l}$ sterile purified water, a mixture of $50 \mu \mathrm{l}$ each of capture Ab-bead reagent and detector Ab-phycoerythrin (PE) reagent. The mixture was subsequently incubated for 3 hours at room temperature, and washed to remove any unbound detector AbPE reagent before data acquisition using flow cytometry. A two colour flow cytometric analysis was performed using a FACScan flow cytometer (Beckton Dickinson Immunocytometry Systems). Data were acquired and analysed using BD cytometric bead array software.

\section{Results}

The concentrations of IL-1 $\beta$, IL-6, IL-10, IL12p70, and TNF- $\alpha$ were not significantly different between basal and reflex tears. In contrast, the concentration of IL-8 was significantly decreased in reflex tears compared with basal tears in each eye (paired $t$ test, $\mathrm{p}<0.01$, fig $\mathrm{l}$ ). In order to illuminate the inter-relation of each cytokine, the ratio of two different cytokines is shown in table 1.

\section{Comment}

Previously published studies have demonstrated that CBA correlates well with enzyme linked immunosorbent assay (ELISA), but the absolute concentrations obtained from each assay were differed for kits of different manufacturers. $^{7}$ Indeed, the concentrations of tear cytokines in the present results were almost equal to the previous report using the same kit. ${ }^{3}$ Nakamura et al performed ELISA for multiple cytokines measuring pooled tears. ${ }^{1}$ The pooled tears enable measurement of multiple cytokines; however the results 

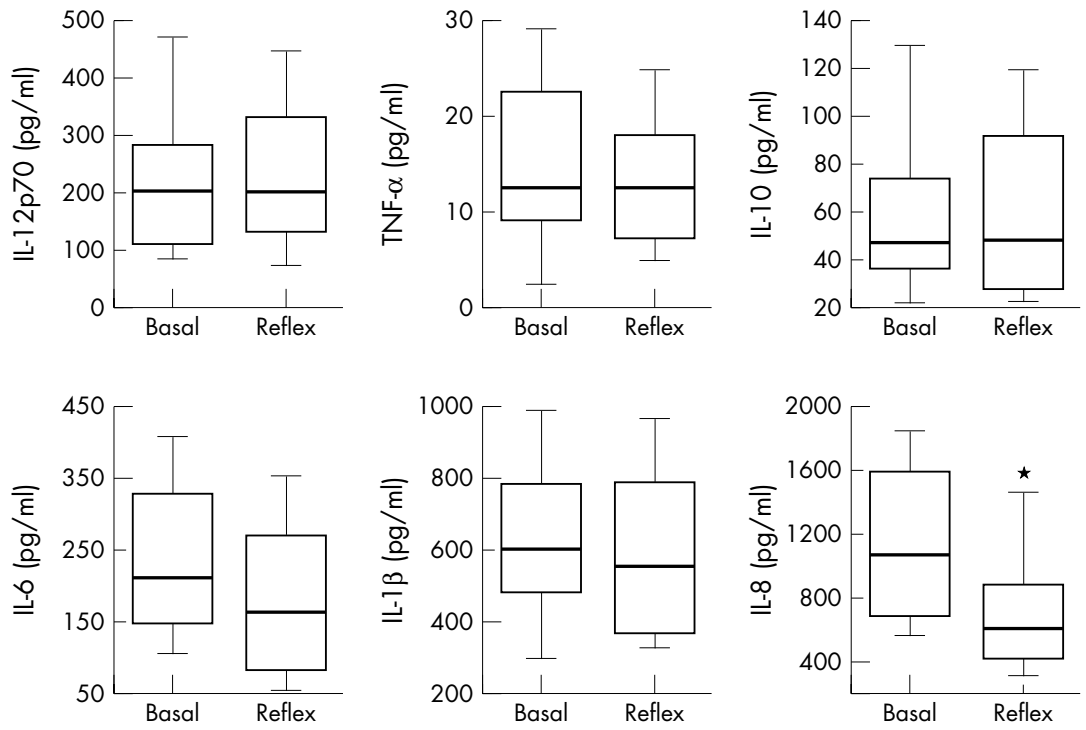

Figure 1 Change of concentrations of cytokines in basal and reflex tears. The concentration of IL$1 \beta, I L-6, I L-10, I L-12 p 70$ and TNF- $\alpha$ are not significantly different between basal and reflex tears. In contrast, IL-8 is significantly less in reflex tears compared with basal tears in each eye (paired $t$ test, ${ }^{*} \mathrm{p}<0.011$.

can be strongly influenced by samples with high concentrations. Because the absolute concentrations of tear cytokines varied widely, this can have a strong bias. In this study, to our knowledge, we measured the multiple cytokines of basal and reflex tears from a single sample for the first time, which can provide concentration ranges for these cytokines in normal subjects that may prove important for studies of ocular inflammation. Of note, only the concentration of IL-8 was decreased more significantly in reflex tears than in basal tears. Maitchouk et al showed that there is no distinctive role of major and accessory glands in secreting basal or reflex tears, thus these tears might be produced primarily by the same tissue and differences might be only the result of the secretory rate of reflex tears. ${ }^{8}$ It was reported that a neuropeptide released from corneal sensory nerves stimulated conjunctival epithelium to secrete IL-8. ${ }^{9}$ Because sensory nerves are present in the cornea so abundantly, IL- 8 can be produced constantly on the ocular surface. IL-8 is a potent pro-inflammatory cytokine, and has a pivotal role in the host defence system. ${ }^{10}$ But excessive IL-8 might be so harmful that constant washout might be helpful for homeostasis of the ocular surface. Indeed, a large amount of IL-8 was found in the tears of dry eyes. ${ }^{11}$ Thus, basal tears might be composed of products of the ocular surface including IL-8 and small amounts of reflex tears that are induced by mild stimulation such as blinks.

In summary, the present study showed that pro-inflammatory and anti-inflammatory cytokines/chemokines are present in the ocular surface even in the absence of inflammation and this was detectable from a small sample of single eyes. Stimulating tears, with the exception of IL-8, has minimal effect on cytokine concentration. We believe the CBA technique can make a valuable contribution in understanding the specific immunopathological mechanisms underlying cytokine interaction with the ocular surface.

S Sonoda, E Uchino, K Nakao, T Sakamoto Department of Ophthalmology Faculty of Medicine, Kagoshima University Graduate School of Medicine and Dental Sciences, Kagoshima, Japan

Correspondence to: Taiii Sakamoto, MD, Department of Ophthalmology, Faculty of Medicine, Kagoshima University Graduate School of Medicine and Dental Sciences, 8-35-1 Sakuragaoka, Kagoshima 890-8520, Japan; tsakamot@m3.kufm.kagoshima-u.ac.jp doi: 10.1136/bjo.2005.076737 Accepted for publication 12 August 2005

\section{References}

1 Nakamura Y, Sotozono C, Kinoshita S Inflammatory cytokines in normal human tears. Curr Eye Res 1998;17:673-6.

2 Lema I, Duran JA. Inflammatory molecules in the tears of patients with keratoconus. Ophthalmology 2005; 112:654-9.

3 Cook EB. Tear cytokines in acute and chronic ocular allergic inflammation. Curr Opin Allergy Clin Immunol 2004:4:441-5.

4 Sack RA, Conradi L, Krumholz D, et al. Membrane array characterization of 80 chemokines, cytokines, and growth factors in open- and closed-eye tears: angiogenin and other defense system constituents. Invest Ophthalmol Vis Sci 2005;46: 1228-38.

5 Fukuda M, Fullard RJ, Willcox MD, et al. Fibronectin in the tear film. Invest Ophthalmol Vis Sci 1996:37:459-67.

6 Chen R, Lowe L, Wilson JD, et al. Simultaneous quantification of six human cytokines in a single sample using microparticlebased flow cytometric technology. Clin Chem 1999:45: 1693-4.

7 Khan SS, Smith MS, Reda D, et al. Multiplex bead array assays for detection of soluble cytokines: comparisons of sensitivity and quantitative values among kits from multiple manufacturers. Cytometry B Clin Cytom 2004;61:35-9.

8 Maitchouk DY, Beuerman RW, Ohta T, et al. Tear production after unilateral removal of the main lacrimal gland in squirrel monkeys. Arch Ophthalmol 2000;1 18 246-52.

9 Tran MT, Ritchie MH, Lausch RN, et al. Calcitonin gene-related peptide induces IL-8 synthesis in human corneal epithelial cells. J Immunol 2000; 164:4307-12.

Table 1 Ratios of cytokine concentration

\begin{tabular}{|c|c|c|c|c|c|c|c|}
\hline & & \multicolumn{6}{|l|}{ B } \\
\hline & & IL-1b & IL-6 & TNF- $\alpha$ & IL-12p70 & IL-10 & IL-8 \\
\hline \multicolumn{8}{|c|}{ (A) Basal tear } \\
\hline & IL-1b & 1 & $3.022(0.246)$ & $54.162(6.549)$ & $3.322(0.316)$ & $12.556(0.889)$ & $0.716(0.086)$ \\
\hline & IL-6 & $0.386(0.037)$ & 1 & $23.568(5.952)$ & $1.238(0.184)$ & $4.705(0.553)$ & $0.246(0.03)$ \\
\hline \multirow[t]{6}{*}{ A } & TNF- $\alpha$ & $0.022(0.002)$ & $0.07(0.008)$ & 1 & $0.074(0.011)$ & $0.275(0.028)$ & $0.017(0.003)$ \\
\hline & IL-12p70 & $0.349(0.026)$ & $0.989(0.071)$ & $18.269(2.086)$ & 1 & $3.981(0.166)$ & $0.261(0.042)$ \\
\hline & IL-10 & $0.087(0.005)$ & $0.253(0.02)$ & $4.518(0.47)$ & $0.261(0.012)$ & 1 & $0.067(0.011)$ \\
\hline & IL-8 & $2.14(0.34)$ & $5.576(0.694)$ & 144.913 (45.971) & $7.447(1.546)$ & $28.257(5.078)$ & 1 \\
\hline & & \multicolumn{6}{|l|}{ B } \\
\hline & & IL-1b & IL-6 & TNF- $\alpha$ & IL-12p70 & IL-10 & IL-8 \\
\hline \multicolumn{8}{|c|}{ (B) Reflex tear } \\
\hline & IL-1b & 1 & $3.71(0.252)$ & $53.061(5.46)$ & $2.918(0.331)$ & $12.012(1.123)$ & $0.972(0.094)$ \\
\hline & IL-6 & $0.304(0.027)$ & 1 & $15.807(1.976)$ & $0.808(0.061)$ & $3.381(0.274)$ & $0.276(0.029)$ \\
\hline \multirow{4}{*}{ A } & TNF- $\alpha$ & $0.021(0.001)$ & $0.078(0.007)$ & 1 & $0.062(0.007)$ & $0.254(0.026)$ & $0.02(0.002)$ \\
\hline & IL-12p70 & $0.390(0.023)$ & $1.361(0.082)$ & $21.357(3.427)$ & 1 & $4.231(0.147)$ & $0.382(0.046)$ \\
\hline & IL-10 & $0.093(0.005)$ & $0.324(0.018)$ & $4.837(0.524)$ & $0.241(0.007)$ & 1 & $0.093(0.012)$ \\
\hline & IL-8 & $1.043(0.231)$ & $4.779(0.665)$ & 73.465 (13.897) & $4.02(0.727)$ & $17.235(3.251)$ & 1 \\
\hline
\end{tabular}


10 Scapini P, Lapinet-Vera JA, Gasperini S, et al. The neutrophil as a cellular source of chemokines. Immunol Rev 2000;177: 195-203.

11 Jones DT, Monroy D, Ji Z, et al. Alterations of ocular surface gene expression in Sjogren's syndrome. Adv Exp Med Biol 1998;438:533-6.

\section{Outcome of implementing the national services framework guidelines for diabetic retinopathy screening: results of an audit in a primary care trust}

Systematic screening for diabetic retinopathy is the key to achieving the targets set out in the recently published national service framework (NSF) guidelines. ${ }^{12}$ One of the two priorities and planning framework (PPF) targets is that by March 2006 a minimum of $80 \%$ of people with diabetes are to be offered screening, rising to $100 \%$ by December 2007. ${ }^{3}$ Digital photography is the modality for screening. ${ }^{5-8}$ The British Diabetic Association has established standards for any diabetic retinopathy screening programme of at least $80 \%$ sensitivity and $95 \%$ specificity.

\section{Screening programme}

Our screening programme was set up to evaluate the existing nationally recommended diabetic retinopathy screening service.

In all, 2165 patients were invited over a period of 12 months; 909 participated. At the screening mydriatric drops ( $1 \%$ tropicamide and $2.5 \%$ phenylephrine) were instilled. The patients were photographed with a Topcon fundus camera and each photograph was screened and graded by consultant ophthalmologists (table 1).

Of the total 909; there were 198 patients with retinopathy (grades R1, M, R2, and R3), 644 patients without retinopathy (grade 0 ), 63 patients with OL (other lesions), and one was (grade U) ungradeable (tables 2 and 3 ). The sensitivity was $98 \%$ and specificity $97 \%$. The retinopathy present was $21 \%$ and the referral rate for retinopathy (STDR) was 7\%; $59 \%$ did not take up the offer to be screened. Some of the reasons cited: 956 (44\%) declined or did not respond, 251 (11\%) are being screened elsewhere, $11(0.5 \%)$ are not diabetic, five $(0.18 \%)$ are dead, six $(0.27 \%)$ are registered blind, and 21 (1\%) have moved.

\section{Comment}

Our screening methods surpassed the standards set by the NICE guidelines. However $59 \%$ of patients did not take up the offer. The achievable standard to which strategic health authorities and primary care trusts are working is $90 \%$ uptake of those offered screening with the minimum standards of $70 \%-80 \%$,

Table 1 Referred patients

\begin{tabular}{llll}
\hline $\begin{array}{l}\text { Diabetic patients type } 1 \\
\text { Invited }\end{array}$ & 93 & Appointment made & 41 \\
$\begin{array}{l}\text { Diabetic patients type } 2 \\
\text { Invited }\end{array}$ & 1442 & Appointment made & 609 \\
$\begin{array}{l}\text { Diabetic patients type not stated } \\
\text { Invited }\end{array}$ & 630 & Appointment made & 259 \\
\hline
\end{tabular}

but even though quality assurance systems are in place uptake is still very poor.

In the intercollegiate audit, led by the Royal College of Ophthalmologists, data were analysed from 9827 patients with diabetes from 129 general practices in 25 health authorities. The lowest level of coverage in a district was $38 \%$ and the highest $85 \%$. In general practice the coverage ranged from $14 \%$ to $97 \%$. The likelihood of having an eye examination was marginally higher in districts with a systematic examination rather than opportunistic or without recognised schemes at all.

In the Hounslow Primary Care Trust our hospital episode statistics (HES) are the only existing screening programme. Patients registered with a GP are referred to the HES for the screening. The reasons for the $44 \%$ who did not respond were that some did not have the time, some were elderly living on their own with nobody to take them, some did not understand the screening leaflet, and some just forgot.

Problems about coverage could be tackled if we had a central electronic database linked to all screening programmes. Although software providers have been agreed for such a data collection exercise, primary care trusts

\begin{tabular}{|c|c|c|}
\hline Grade & Sex & Total \\
\hline \multirow[t]{3}{*}{0} & $M$ & 363 \\
\hline & $\mathrm{F}$ & 261 \\
\hline & $\mathrm{T}$ & 624 \\
\hline \multirow[t]{3}{*}{$\mathrm{R} 1$} & $M$ & 74 \\
\hline & $\mathrm{F}$ & 54 \\
\hline & $\mathrm{T}$ & 128 \\
\hline \multirow[t]{3}{*}{$M$} & $M$ & 23 \\
\hline & $\mathrm{F}$ & 21 \\
\hline & $\mathrm{T}$ & 44 \\
\hline \multirow[t]{3}{*}{ R2 } & $M$ & 17 \\
\hline & $\mathrm{F}$ & 9 \\
\hline & $\mathrm{T}$ & 26 \\
\hline \multirow[t]{3}{*}{ R3 } & $M$ & 1 \\
\hline & $\mathrm{F}$ & 0 \\
\hline & $\mathrm{T}$ & 1 \\
\hline \multirow[t]{3}{*}{$\mathrm{OL}$} & $M$ & 33 \\
\hline & $\mathrm{F}$ & 30 \\
\hline & $\mathrm{T}$ & 63 \\
\hline \multirow[t]{3}{*}{$U$} & $M$ & 0 \\
\hline & $\mathrm{F}$ & 1 \\
\hline & $\mathrm{T}$ & 1 \\
\hline
\end{tabular}

have yet to implement this. People unable to attend during the week could be accommodated in weekend or evening clinics. These clinics could also be reserved, with bilingual support workers to explain the importance of screening for the ethnic patients. Community networks like the rotary, patient groups, ethnic resource centres, and senior citizens groups can be used. The National Service Framework targets will be achieved only if the diabetic population is convinced of the importance of screening.

M J Saldanha, U Meyer-Bothling Ashford and St Peter's NHS Trust

Correspondence to: Mr Mario J Saldanha, Ashford and St Peter's NHS Trust, Ashford, TW15 3AA, UK; mariosaldanha@yahoo.com

doi: $10.1136 /$ bjo. 2005.076760

Accepted for publication 29 August 2005

Competing interests: none.

\section{References}

1 Department of Health. National service framework for diabetes. The standards. London: DoH, December, 2001

2 Department of Health. National service framework for diabetes. Delivery strategy. London: DoH, 2003.

3 Garvican L, Scanlon P. Quality assurance for the national screening programme for sight threatening diabetic retinopathy: development of a set of key quality assurance standards. September, 2003.

4 National Diabetes Support Team. Fact sheet No 5, hitting the target for retinopathy screening. July, 2004.

5 Buxton MJ, Sculpher MJ, Ferguson BA, et al. Screening for treatable diabetic retinopathy: a comparison of different methods. Diabet Med 1991;8:371-7.

6 Gibbins RL, Owens DR, Allen JC, et al. Practical application of the European Field Guide in screening for diabetic retinopathy by using ophthalmoscopy and $35 \mathrm{~mm}$ retinal slides. Diabetologia 1998:41:59-64.

7 O'Hare JP, Hopper A, Madhaven C, et al. Adding retinal photography to screening for diabetic retinopathy: a prospective study in primary care. BMJ 1996:312:679-82.

8 Harding SP, Broadbent DM, Neoh C, et al. Sensitivity and specificity of photography and direct ophthalmoscopy in screening for sight threatening eye disease: the Liverpool diabetic eye study. BMJ 1995;311:1131-5.

9 Audit Commission. Testing times. A review of diabetic services in England and Wales. London: Department of Health, Audit Commission, 2000

Table 3 Final data

\begin{tabular}{|c|c|c|c|c|c|c|c|c|c|}
\hline $\begin{array}{l}\text { Total } \\
\text { patients } \\
\text { screened }\end{array}$ & $\begin{array}{l}\text { Sample } \\
\text { size }\end{array}$ & Ungradable & $\begin{array}{l}\text { True } \\
\text { positives }\end{array}$ & $\begin{array}{l}\text { False } \\
\text { negatives }\end{array}$ & $\begin{array}{l}\text { True } \\
\text { negatives }\end{array}$ & $\begin{array}{l}\text { False } \\
\text { positive }\end{array}$ & Sensitivity & Specificity & $\begin{array}{l}\text { Retinopathy } \\
\text { present }\end{array}$ \\
\hline 909 & 909 & 1 & 198 & 4 & 644 & 8 & $98 \%$ & $97 \%$ & $21.78 \%$ \\
\hline
\end{tabular}




\section{Late improvement in upward gaze in a patient with hydrocephalus related Parinaud dorsal midbrain syndrome}

Acute hydrocephalus is a common cause of the Parinaud dorsal midbrain syndrome. ${ }^{12}$ Most patients with this condition improve either immediately following treatment of the hydrocephalus or within a few months, and it is generally assumed that those who do not do so have no potential for subsequent improvement. I recently evaluated a patient whose upward gaze spontaneously improved $4 \frac{1}{2}$ years after treatment of trauma related hydrocephalus.

\section{Case report}

A 23 year old Asian man was in his usual excellent general and ocular health until October 2000, when he was struck by a car while walking across the street. He was taken to a local hospital where he was found to have extensive injuries, including bilateral subdural and epidural haematomas. He also had evidence of increased intracranial pressure and required an emergency cranial decompression. Postoperatively, he was evaluated by a neuro-ophthalmologist who noted that the patient's only ocular disturbance was a mild left trochlear nerve paresis. The paresis resolved within about 3 weeks.

About 6 months after the injury, the patient developed severe headaches and double vision. He was evaluated by the same neuro-ophthalmologist who had evaluated him previously. He noted that the patient now had a severe dorsal midbrain syndrome characterised by lack of elevation of either eye above the midline associated with an exotropia of 25-30 prism dioptres at distance and near, and a left hypotropia of 5 prism dioptres. An evaluation that included neuroimaging and measurement of intracranial pressure revealed hydrocephalus, and the patient underwent placement of a ventriculoperitoneal shunt with normalisation of intracranial pressure, resolution of neuroimaging evidence of hydrocephalus, and resolution of headaches but without any change in ocular motility or alignment. He was eventually referred to the neuro-ophthalmology unit of the Wilmer Eye Institute at the Johns Hopkins Hospital for evaluation and management.

The patient was examined by me for the first time in September 2001, 11 months after the original injury and about 5 months after he had first been noted to have a dorsal midbrain syndrome. At that time, the examination revealed visual acuity of 20/20 in both eyes at distance and near. Automated perimetry revealed bilateral, incomplete, congruous, superior homonymous quadrantic field defects. Pupils were normally reactive to both light and near stimulation. In primary position, the patient had a 25 prism dioptre exotropia that increased to 35 prism dioptres on attempted right gaze and decreased to 15 prism dioptres on attempted left gaze. There was also a 5 prism dioptre left hypotropia. Both eyes could elevate just barely to the midline. There was no difference in degree of elevation with pursuit versus saccades, and elevation did not improve with the oculocephalic manoeuvre. Lateral gaze and downgaze were normal bilaterally for both pursuit and saccadic eye movements. I recommended consideration of strabismus surgery and asked the patient to return in
4 months for reassessment. He did so in January 2002, at which time his ocular motility and alignment were stable. Specifically, neither eye was able to elevate above the midline, either voluntarily or by the oculocephalic manoeuvre.

In May 2002, I performed a left lateral rectus muscle recession of $7.5 \mathrm{~mm}$ and a left medial rectus resection of $6.5 \mathrm{~mm}$ with superior transposition of both the lateral and medial rectus muscles one muscle width. Postoperatively, the patient had excellent horizontal alignment, although he still had a small left hypotropia of about 5 prism dioptres and was still unable to elevate either eye above the midline.

I subsequently followed the patient at regular intervals. When I examined him in April 2004, he had no change in his ocular motility or alignment, and I recommended that he consider obtaining a small vertical prism to try to eliminate his residual vertical diplopia. I also recommended that he return in 1 year for reassessment. He did so in August 2005.

When I examined the patient in August 2005, he indicated that he thought his vision had improved. He stated that although he was aware of some double vision, it was somewhat less than it had been previously. He also thought his eyes were "moving better."

On examination, the patient's visual acuity with correction was 20/15 in each eye at distance and $\mathrm{Jl}$ in each eye at near. Colour vision testing using Hardy-Rand-Rittler pseudoisochromatic plates was 10/10 bilaterally. Visual fields were performed by static technique and showed stable bilateral, incomplete, congruous, superior homonymous quadrantic defects, consistent with damage to both inferior occipital lobes. Pupils were isocoric and normally reactive to light and near stimulation. The patient had full abduction, adduction, and infraduction of both eyes. In addition, he now was able to elevate both eyes about $35^{\circ}$ above the midline. He had normal velocity saccades in all directions, but he developed convergence-retraction nystagmus when looking at an optokinetic drum whose targets were being rotated downward. When the targets were moving upward, to the right, or to the left, the response was normal. In primary position, the patient had a 4 prism dioptre intermittent left hypotropia at distance and near, associated with $4^{\circ}$ of intorsion of the left eye using double Maddox rods. He was most comfortable with a 4 prism dioptre prism placed base up over the left spectacle lens, and a Fresnel prism of this strength and orientation was placed on the left lens of his glasses. He had no ptosis or lid retraction, and the results of slit lamp biomicroscopy, applanation tonometry, and ophthalmoscopy were normal.

\section{Comment}

The dorsal midbrain syndrome of Parinaud usually results from damage to premotor pathways for binocular upward gaze in the dorsal mesencephalon. ${ }^{2}$ Depending on the extent of damage, the patient may have pursuit saccadic dissociation, with better upward gaze during pursuit than when attempting upward saccades, and some patients have improved upward gaze with the oculocephalic manoeuvre, indicating sparing of infranuclear pathways. The dorsal midbrain syndrome may be caused by extrinsic or intrinsic lesions, with hydrocephalus being a common aetiology in some series. ${ }^{13}$ Depending on the nature and extent of damage as well as the length of time the condition has been present before the underlying disorder is treated, some patients improve, often substantially, whereas others do not. In general, patients whose underlying condition is treated successfully but who do not improve within a few weeks to months are thought to have no potential to improve; however, our patient's spontaneous improvement about $4 \frac{1}{2}$ years after onset and treatment of the underlying condition indicates that some patients retain the potential to improve even after several years have passed. This information may be of value in counselling patients with the dorsal midbrain syndrome who ask if there is any chance of improvement when none has occurred after months to a few years.

Correspondence to: N R Miller, Wilmer Eye Institute, Johns Hopkins Hospital, 600 North Wolfe Street, Baltimore, MD 21287, USA; nrmiller@jhmi.edu doi: $10.1136 /$ bjo.2005.081810

Accepted for publication 7 September 2005

\section{References}

1 Keane JR. The pretectal syndrome: 206 patients. Neurology 1990;40:684-90.

2 Zee DS, Newman-Toker D. Supranuclear and internuclear ocular motility disorders. In Miller NR, Newman NJ, Biousse V, et al. Walsh and Hoyt's clinical neuro-ophthalmology. 6th ed. Vol 1. Baltimore: Lippincott, Williams \& Wilkins, 2005:907-67.

3 Rowe FJ. The presenting features of Parinaud's dorsal midbrain syndrome. Br Orthopt $J$ 1997:54:20-3.

\section{MAILBOX}

\section{Purification of triamcinolone acetonide suspension for intravitreal injection}

In the article by García-Arumí and associates, ${ }^{1}$ the authors reported the results of several techniques used for purification of triamcinolone acetonide suspension for intravitreal injection (two filter and two non-filter techniques). I very much appreciate that they finally recommended our method (centrifugation for 5 minutes at $3000 \mathrm{rpm}$ with extraction of $0.9 \mathrm{ml}$ of the supernatant and pellet resuspension with $0.9 \mathrm{ml}$ of balanced salt solution, BSS) among those compared. ${ }^{2}$

This could have been an interesting report but I want to raise some important issues mentioned in their paper. The source of the evaluated techniques was not clearly specified by the authors. Are they previously published techniques? Are they techniques developed entirely by García-Arumí et al? As far as I know, the centrifugation technique described by García-Arumí et al was first reported by Hernaez-Ortega in $2003^{3}$ and it was first published by Hernaez-Ortega and myself in the 2004 July/August issue of Ophthalmic Surgery, Lasers \& Imaging. ${ }^{2}$ In fact, the term "purification" was first applied to removal of most of the vehicle from a commercially available triamcinolone acetonide suspension by us.

Parametric tests tend to be more powerful than non-parametric tests if their distributional assumptions are met. However, non-parametric methods require fewer 
assumptions, and they are generally robust against problems like outliers and non-constant variances. The authors tested statistical significance by the Kruskal-Wallis test, a non-parametric procedure that is a $\mathrm{K}$-sample generalisation of the two sample rank sum test (also called the Mann-Whitney U test). It tests the null hypothesis of identical group medians, rather than means. With the data available in this report, the authors should have noticed that figures 1 and 2 show means and standard deviations; they should instead have shown group medians. Moreover, their results should have been expressed as medians. ${ }^{4}$ It also remains unclear how many assays were performed. By looking at figures 1 and 2, it seems that three assays were done each time but somehow they were done in duplicate. This is important to show the real sample size that was used to compute the estimates.

The pellet resuspension with $0.9 \mathrm{ml}$ of BSS in the centrifugation technique appeared in their final recommendation at the end of the paper. However, the authors stated in the methods section that the pellet was resuspended with $1 \mathrm{ml}$ of BSS. This point needs to be explained.

I recommend that the authors clarify the above mentioned issues. I also suggest that they learn the golden rule of fair use of another author's protected material: take from someone else only what you wouldn't mind someone taking from you.

Correspondence to: Dr Enrique Soto-Pedre, European Innovative Biomedicine Institute, $\mathrm{C} /$ Jardines \#2, Apt 1-G, 39700 Castro-Urdiales, Cantabria, Spain; eibi@ eurodiab.com

The author does not have commercial interest in any product mentioned in the manuscript. doi: 10.1136/bjo.2005.083501

Accepted for publication 26 September 2005

\section{References}

1 García-Arumí J, Boixadera A, Giralt J, et al. Comparison of different techniques for purification of triamcinolone acetonide suspension for intravitreal use. $\mathrm{Br} J$ Ophthalmol 2005;89:1112-14.

2 Hernaez-Ortega MC, Soto-Pedre E. A simple and rapid method for purification of triamcinolone acetonide suspension for intravitreal injection. Ophthalmic Surg Lasers Imaging 2004;35:350-1.

3 Hernaez-Ortega MC. [Intraocular steroids]. Arch Soc Esp Offalmol 2003;78:523-4.

4 Snedecor GW, Cochran WG. Statistical methods, 5th ed. Ames, lowa: lowa State University Press, 1989

\section{PHEMA as a keratoprosthesis material}

An aim to provide an optimised keratoprosthesis, with excellent biointegration, and all other properties meeting ideal requirements, is one we share with Mehta et al. ${ }^{1}$ However, their paper includes some points that require clarification.

PHEMA (poly(2-hydroxyethyl methacrylate) is a non-toxic polymer of the toxic monomer HEMA, though cytotoxicity is still possible if non-reacted monomer has not been fully removed. The "polyhydroxyethyl methacrylate" the authors obtained for their study was not fully described, and may have been contact lens blanks, unlikely to have been processed for "implantable quality." Whether the samples had been fully extracted was not stated, nor was the hydration of the samples when used for the study. Contact lens blanks are not designed for cell adhesion and the results of this study, with regard to PHEMA, are entirely predict able and have been previously reported.

The commercially available keratoprosthesis AlphaCor is made from a form of PHEMA, specifically modified for its intended purpose within the cornea. In particular, the AlphaCor OPTIC is made from a relatively low water content, but hydrated, microporous form, similar to the samples evaluated by the authors, specifically because it does not encourage cellular adhesion (epithelial coverage is not desired for this model, nor would adherent posterior cells and membranes be desirable).

In contradistinction, the biointegratable SKIRT region of AlphaCor is made from a macroporous form of PHEMA with a very high water content; this material, with its interconnecting channels, has been optimised to promote viable biocolonisation, which has been extensively described in the literature. Mehta et al do concede that cells "may behave differently in colonising a $3-\mathrm{D}$ porous keratoprosthesis skirt": indeed they do. Further very subtle modifications of the sponge structure significantly affect all aspects of biointegration.

Both early trial results, such as the preliminary cases cited by Mehta et al, and current results for over 250 AlphaCor devices have been extensively presented and made available to all device users. Histology now available from AlphaCor devices explanted from human recipients confirms that the biointegration process in humans is similar to that previously shown in the animal model and maintained in the long term. As expected, specific inflammatory processes can cause localised reversal of biointegration in areas of stromal melting Certainly, porosity itself does not prevent melting processes, as is also seen in relation to hydroxyapatite keratoprostheses and orbital implants.

There is no argument that keratoprosthesis materials and design require ongoing revision and improvement. The authors' findings in relation to hydroxyapatite are interesting although, as they note, this rigid material has its own limitations. Novel approaches are undergoing early evaluation and may offer benefits. However, at present, in our view, AlphaCor is a device worthy of consideration for those in whom a donor graft would fail

\section{R Hicks, T V Chirila, S Vijayasekaran, G J Crawford}

Lions Eye Institute, Perth, Western Australia

Correspondence to: Celia Hicks, Lions Eye Institute, Perth, Western Australia; crhicks@cyllene.uwa.edu.au doi: 10.1136/bjo.2005.084855

\section{Accepted for publication 11 October 2005}

$\mathrm{CH}$ is medical director of CooperVision Surgical, manufacturer of AlphaCor. The Biomaterials and Polymer Research Department of the Lions Eye Institute has a financial interest in CooperVision Surgical through support of departmental funding, travel, and research.

\section{Reference}

1 Mehta JS, Futter CE, Sandeman SR, et al. Hydroxyapatite promotes superior keratocyte adhesion and proliferation in comparison with current keratoprosthesis skirt materials. Br J Ophthalmol 2005;89:1356-62.

\section{Expression of TSH-R in normal human extraocular muscles}

We read with interest the paper published by Boschi et al, ${ }^{1}$ in which immunohistochemistry was performed on orbital tissues from patients with thyroid associated ophthalmopathy (TAO) and compared with non-diseased orbital tissue.

Our laboratory recently reported positive TSH receptor staining within normal human muscle fibres, using one of the same antibodies (3G4) as Boschi et al (supplied by Costagliola) and a commercial antibody (3B12). ${ }^{2}$

Our findings differ from Boschi et al's as no staining of the muscle fibres was visible in their experience.

Assessing the techniques used suggested some possibilities as to why our findings differ. Our paraffin embedded tissues were subjected to a proteolytic antigen retrieval step, as commonly used in avidin-biotin staining. ${ }^{3}$ The reason for this is that formalin used in fixation is notorious for altering protein immunoreactivity, and hence masking protein expression. ${ }^{4}$

Moreover, the amplification immunohistochemistry kit used in our experiments is possibly more sensitive than conventional immunohistochemistry used in the experiments of Boschi et al. ${ }^{6}$

We do not dispute the finding that TSH-R expression is elevated in orbital connective tissue of diseased patients. Combined with our findings, Boschi et al's paper also suggests that expression of TSH-R on normal muscle fibres is lower than in the connective tissue of diseased patients. Boschi et al have successfully produced more evidence that connective tissues in the orbit are active in TAO affected patients; however, the potential role of the extraocular muscle in the pathogenesis of TAO should also be considered.

S J Kloprogge, A G Frauman Department of Medicine, University of Melbourne, Clinical Pharmacology and Therapeutics Unit, Level 5 Lance Townsend Building, Austin Health, Studley Road, Heidelberg, Victoria, 3084, Australia

Correspondence to: Mr Steven Kloprogge, Department of Medicine, University of Melbourne Clinical Pharmacology and Therapeutics Unit, Level 5

Lance Townsend Building, Austin Health, Studley Road, Heidelberg, Victoria, 3084, Australia; s.kloprogge@pgrad.unimelb.edu.au doi: 10.1136/bjo.2005.084863

Accepted for publication 11 October 2005

\section{References}

1 Boschi A, Daumerie C, Spiritus $M$, et al. Quantification of cells expressing the thyrotropin receptor in extraocular muscles in thyroid associated orbitopathy. $\mathrm{Br} J$ Ophthalmol 2005;89:724-9.

2 Kloprogge SJ, Busuttil BE, Frauman AG. TSH receptor protein is selectively expressed in normal human extraocular muscle. Muscle Nerve 2005;32:95-8. 
3 Thompson LD, Miettinen M, Wenig BM Sinonasal-type hemangiopericytoma: a clinicopathologic and immunophenotypic analysis of 104 cases showing perivascular myoid differentiation. Am J Surg Pathol 2003;27:737-49.

4 Fox $\mathrm{CH}$, Johnson $\mathrm{FB}$, Whiting J, et al. Formaldehyde fixation. J Histochem Cytochem 1985:33:845-53.

5 Puchtler H, Meloan SN. On the chemistry of formaldehyde fixation and its effects on immunohistochemical reactions. Histochemistry 1985;82:201-4.

6 Erber WN, Willis JI, Hoffman GJ. An enhanced immunocytochemical method for staining bone marrow trephine sections. J Clin Pathol 1997; 50:389-93.

\section{Trabeculotomy versus trabeculotomy-trabeculectomy for congenital glaucoma}

The article by Al-Hazmi et al ${ }^{1}$ states that combined trabeculotomy-trabeculectomy with mitomycin C (CTTM) gave better results than trabeculotomy alone for primary congenital glaucoma (PCG) at the King Khaled Eye Specialist Hospital (KKESH) in Riyadh, Saudi Arabia, between 1982 and 2002. For moderate PCG the success rate is stated as $40 \%$ and $80 \%$ for trabeculotomy and CTTM, respectively. For severe PCG the stated success rate is $10 \%$ and $70 \%$ for trabeculotomy and CTTM, respectively. However, without more specific information regarding when the trabeculotomies were performed at KKESH, the authors cannot advocate CTTM over trabeculotomy for moderate and severe PCG.

As the article states, over the years at KKESH the success rate for trabeculotomy for PCG dramatically improved (29\% from 1982 90; 47\% from 1991-4; 82\% from 1995-2002) The authors attribute these improved results over the years to improved primary healthcare facilities within the kingdom, earlier referrals, better equipment availability, and surgeons becoming more adept at surgical intervention. In contrast, CTTM for PCG was first performed at KKESH in 1994 with less of a "learning curve"; the success rate from 1994-2002 was $72 \%$. The complication rate, however, was higher for CTTM than for trabeculotomy.

Because initial trabeculotomy success for PCG at KKESH has dramatically increased with time, it is important to know how many of the reported trabeculotomy failures for moderate and severe PCG were from the earlier periods in the hospital. This information was not in the paper. It may be that trabeculotomy as currently performed at KKESH for moderate and severe PCG has a success rate similar to that of CTTM for the same patient population with fewer surgical complications.
Correspondence to: A O Khan, King Khaled Eye Specialist Hospital, PO Box 7191, Riyadh, Saudi Arabia; arif.khan@mssm.edu

doi: 10.1136/bjo.2005.084871

Accepted for publication 11 October 2005

\section{Reference}

1 Al-Hazmi A, Awad A, Zwaan Z, et al. Correlation between surgical success rate and severity of congenital glaucoma. Br J Ophthalmol 2005;89:449-53.

\section{CORRECTIONS}

doi: 10.1136/bjo.2005.66431corr 1

The letter titled, Bevacizumab suppresses choroidal neovascularisation caused by pathological myopia $(B r \quad J$ Ophthalmol 2005;10:1368-87), was previously published online at http://bjo.bmjjournals.com/cgi/ content/full/89/6/el.

\section{doi: 10.1136/bjo.2005.68171 corrl}

In the paper titled, The achiasmia spectrum: congenitally reduced chiasmal decussation (Br J Ophthalmol 2005;89:1311-17), one of the authors names has been misspelt. The correct list of authors is, D A Sami, D Saunders, D A Thompson, I M RussellEggitt, K K Nischal, G Jeffrey, M Dattani, R A Clement, A Liasis, D S Taylor. The journal apologises for this error.

\section{doi: 10.1136/bjo.2005.bj75184corr l}

In the letter titled, Two novel mutations of connexion genes in Chinese families with atuosomal dominant congenital nuclear cataract (Br J Ophthalmol 2005;11:1535-6), the authors have be listed incorrectly. The correct listing is, Z W Ma, J Q Zheng, J Li, X R Li, X Tang, X Y Yuan, X M Zhang, H M Sun.

doi: 10.1136/bjo.2005.bj82453corrl

In the mailbox item titled, TTT: local light absorption and heat convection versus heat (Br J Ophthalmol 2005;11:1544-5), the second author's name has been misspelt. The correct spelling is D H Sliney. The journal apologises for this error.

doi: 10.1136/bjo.2005.bj74468corrl

In the letter titled, Confocal microscopy of the cornea in nephropathic cystinosis $(\mathrm{Br} J$ Ophthalmol 2005;89:1530-1), the order of the authors is incorrect. The correct order is A H Alsuhaibani, A O Kahn, M D Wagoner. The journal apologises for this error.

\section{NOTICES}

\section{World Ophthalmology Congress 2006 - Brazil}

The World Ophthalmology Congress (which is replacing the International Congress of Ophthalmology) is meeting in February 2006 in Brazil.

For further information on the congress and committees, scientific program and coordinators of different areas are available at the congress website www.ophthalmology 2006.com.br

\section{$19^{\text {th }}$ International Society for Geographical \& Epidemiological} Ophthalmology Congress

The $19^{\text {th }}$ ISGEO congress will be held in Sao Paulo, Brazil on 18-19 February, 2006, just prior to the ICO. Abstract submission and registration forms can be obtained by emailing Dr Paul Courtright (pcourtright@kcco. net) or by accessing the ISGEO website at www.kcco.net/isgeo.

\section{EYE INJURIES}

The latest issue of Community Eye Health (No 55) discussed the assessment and management of eye injuries in the developing world. For further information please contact: Journal of Community Eye Health, International Resource Centre, International Centre for Eye Health, Department of Infectious and Tropical Diseases, London School of Hygiene and Tropical Medicine, Keppel Street, London WCIE 7HT, UK (tel:

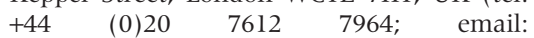
Anita.Shah@lshtm.ac.uk; online edition: www.jceh.co.uk). Annual subscription (4 issues) UK $£ 28 /$ US\$45. Free to developing country applicants.

\section{$8^{\text {th }}$ EUNOS Meeting - 2007}

The 2007 European Neuro-ophthalmology Society meeting (EUNOS; www.eunos.web.org) will be taking place in Istanbul, Turkey on 26-29 $9^{\text {th }}$ May 2007. For further information please visit www.eunos2007.org, email: or contact Pinar Aydin aydinp@ eunos2007.org.

\section{Teaching courses on Retinal and Vitreous Surgey}

Several teaching courses on Retinal and Vitreous Surgery have been organised throughout 2006 and 2007 around the world in association with the International Faculty. For further information on each of these courses please contact Ingrid Kressig, Univ. Augenklinik Theodor-Kutzer-Ufer 1-3, 68164 Mannheim, Germany; email: Ingrid.kreissig@ augen.ma.uni-heidelberg.de; website: http:// kressig.uni-hd.de/. 